Article

\title{
Enhanced Dielectric Permittivity of Optimized Surface Modified of Barium Titanate Nanocomposites
}

\author{
Udhay Sundar ${ }^{1}$, Zichen Lao ${ }^{2}$ (1) and Kimberly Cook-Chennault ${ }^{2,3, *}$ \\ 1 Portland Technology Development, Intel Corporation, Portland, OR 97124, USA; udhay.sundar@gmail.com \\ 2 Mechanical Engineering and Applied Mechanics, University of Pennsylvania, Philadelphia, PA 19104, USA; \\ lao0910@seas.upenn.edu \\ 3 Mechanical and Aerospace Engineering, Rutgers, the State University of New Jersey, Piscataway, \\ NJ 08854, USA \\ * Correspondence: cookchen@soe.rutgers.edu; Tel.: +1-848-445-0429
}

Received: 31 January 2020; Accepted: 16 March 2020; Published: 5 April 2020

check for updates

\begin{abstract}
High permittivity polymer-ceramic nanocomposite dielectric films take advantage of the ease of flexibility in processing of polymers and the functionality of electroactive ceramic fillers. Hence, films like these may be applied to embedded energy storage devices for printed circuit electrical boards. However, the incompatibility of the hydrophilic ceramic filler and hydrophobic epoxy limit the filler concentration and therefore, dielectric permittivity of these materials. Traditionally, surfactants and core-shell processing of ceramic fillers are used to achieve electrostatic and steric stabilization for adequate ceramic particle distribution but, questions regarding these processes still remain. The purpose of this work is to understand the role of surfactant concentration ceramic particle surface morphology, and composite dielectric permittivity and conductivity. A comprehensive study of barium titanate-based epoxy nanocomposites was performed. Ethanol and 3-glycidyloxypropyltrimethoxysilan surface treatments were performed, where the best reduction in particle agglomeration, highest value of permittivity and the lowest value of loss were observed. The results demonstrate that optimization of coupling agent may lead to superior permittivity values and diminished losses that are $\sim 2-3$ times that of composites with non-optimized and traditional surfactant treatments.
\end{abstract}

Keywords: dielectric; capacitor; embedded energy storage; permittivity

\section{Introduction}

Dielectric materials are ubiquitously used today and novel materials with extraordinary properties are being explored for advanced applications, such as electric stress control for cables and joints to shield current loss at concentrated points, energy storage as capacitors [1-3], embedded passive devices, photovoltaics and battery electrode materials that enhance the ionic conductivity and thermal stability of the electrolyte as shown in Figure 1. Typically, materials used in these applications must possess high dielectric and mechanical strength, high thermal conductivity to alleviate thermal stresses, good ductility, and high glass transition and curie temperatures to prevent premature failure.

Either ceramic dielectric oxides or polymers are used for majority of the aforesaid applications because ceramic oxides possess high dielectric permittivity $\left(\varepsilon_{\mathrm{r}}=200-10,000\right.$ [4-7]) and high stiffness (elastic modulus between 50-100 GPa [8-11]). These materials also suffer from high dielectric loss over broad frequency bands and relatively high mechanical stiffness, which makes them susceptible to premature failure when subjected to extensive cyclic operation and inherently low breakdown field strength. These characteristics limits their available energy density for many operations such as energy storage and IOT applications. Polymer-based dielectric materials, on the other hand, have high 
breakdown field strengths, low dielectric losses and are inherently ductile. These inherent properties make them easy to process into various shapes and films and easier to 3D print. Nevertheless, these materials have very low dielectric permittivity and lower mechanical stiffness.

\begin{tabular}{|l|l|l|}
\hline \multicolumn{2}{|l|}{ Applications of Smart Materials and Systems } & Future Applications \\
\hline Wearables & Prosthetics/Robotics & Internet of Things \\
\hline Implantable Devices & Energy Harvesting & $\begin{array}{l}\text { Mobile Healthcare } \\
\text { (mHealth) }\end{array}$ \\
\hline Portable Devices & Communication & \\
\hline & & \\
\hline
\end{tabular}

Figure 1. Overview of uses and applications of the proposed materials.

Embedded capacitor technology is an important technique for miniaturization and production of high performance of electronic packaging systems. High dielectric constant $\left(\varepsilon_{\mathrm{r}}\right)$ polymer-ceramic composites have been of great interest as embedded capacitor materials because of their ease of fabrication, compatibility with printed wiring board (PWB) technology, and high relative permittivity $(5-20,000)$ [12-15]. In order to design more effective capacitors, it is essential to achieve high permittivity of the composite. Many workers have demonstrated that the dielectric constants of polymer-ceramic composites could be enhanced by adding conductive particles in insulative polymeric matrix as a third phase in the composite [16-20]. This enhances the overall permittivity of the composite by forming conductive networks. However, these composites suffer from high dielectric losses due to increased dielectric loss and low breakdown strengths, which makes them less amenable to electrical polarization [21-23].

In general, composites that contain high filler loadings (vol. \% > 50) exhibit high overall permittivity values. Nanoparticles in polymer matrices have several advantages over homogenous ceramic dielectric materials. Some of these advantages include enhanced dielectric breakdown strength and improved voltage endurance over the life of the sample [24,25]. A minor stumbling block is the proclivity of nanoparticles to agglomerate by forming aggregates within the matrix [26,27]. This agglomeration is attributed to two main factors: high surface area to volume ratios and van der Waals forces that arise between all molecules and particles. High surface area to volume rations causes nanoceramic particles to form bonds with one another, in order to diminish the surface energy. The second factor, van der Waals forces, arise between all molecules and particles. Nanoparticles of metals, metal oxides and ceramic materials that are not coated have robust van der Waals forces [26,27]. Inter-particle agglomeration dues to surface energy can be reduced by using surfactants and coupling agents that form covalent bonds with the nanoparticles.

Moreover, the incompatibility of inorganic-organic constituent materials in the composite exacerbate difficulties in processing of these films $[13,14,28-31]$. The surface of $\mathrm{BaTiO}_{3}$ particles in $\mathrm{BaTiO}_{3} /$ epoxy composites have residual hydroxyl groups, which are hydrophilic in nature. On the 
other hand, the epoxy resin and organic solvent used in the composite are hydrophobic. Therefore, $\mathrm{BaTiO}_{3}$ tends to agglomerate and separate from the organic solvent or resin, which causes processing difficulties $[13,14,32]$. Hence, dielectric polymer nanocomposites that have high-volume fractions of ceramic filler have been of interest due to obstacles associated with processing and particle dispersion.

Identification parameters pertaining to the surface modification of ceramics could address both of these problems. For example, researchers have looked at modifying $\mathrm{BaTiO}_{3}$ by treating it with hydrogen peroxide to hydroxylate the surface [33-37]. The compatibility between the inorganic fillers and polymer materials can be enhanced with the use of surface modifiers such as macromolecular surface modifiers $[38,39]$ and small-molecular weight surface active agents, such as, silane and titanate coupling agents [40-43]. Coupling agents such as these have two functional groups, wherein one reacts with either $\mathrm{BaTiO}_{3}$ and the other with the epoxy by forming covalent bonds. Silane coupling agents were studied in dielectric polymer composites such as epoxy/aluminum [44] and epoxy/fosterite $\left(\mathrm{Mg}_{2} \mathrm{SiO}_{4}\right)$ [45].

Zhou et al. [44] surface treated aluminum filler with coupling agents (silane KH550, silane KH560, titanate NXT-102, titanate NXT-201) prior to embedding the filler into a diglycidyl ether of bisphenol A-type epoxy resin, and examined the aluminum filler microstructure and composite dielectric properties. In this study, the concentration of $\mathrm{Al}$ filler ranged from 0 to $70 \%$ by weight. It was found that the surface treatment of the aluminum, rendered enhanced dielectric constants, e.g., 34 juxtapose 19.6 for treated and pristine filler aluminum powder at $70 \%$ weight concentration, respectively and reduced dielectric loss values. It was concluded that the use of coupling agents improved the interfacial bonding strength between the aluminum and the epoxy resin and decreased the voids and defects at the phase interfaces. These workers also indicated that the $\mathrm{KH}-560$ silane coupling agent had an epoxide as one of its end groups, and three hydroxyls at its other end after reacting with the Al particles. Others such as Sasikala et al. [45] investigated the influence of silane coupling agents on the microstructure, dielectric and thermal properties of epoxy-forsterite $\left(\mathrm{Mg}_{2} \mathrm{SiO}_{4}\right)$ composites. In this work, it the dielectric permittivity was found to increase with the composite fabricated using silane coupling agent due to uniform dispersion of the filler within the matrix leading to enhanced polarization from the increased dipole-dipole interaction [46]. In this work, the dielectric permittivity was found to be $\sim 3.7$ and $\sim 3.9$ at $7 \mathrm{GHz}$ for untreated and surface treated fillers, respectively. Similarly, Iijima et al. [21] modified the surface of $\mathrm{BaTiO}_{3}$ particles using by a combination of 3-glycidoxypropyltrimethoxysilane (GPTMS) and a variety of solvents, where the goal was to examine the effects the GPTMS and solvents on composite performance. In this work, the particles were modified in water, ethanol and xylene, along with GPTMS. At $1 \mathrm{kHz}$ the dielectric constant for $\mathrm{BaTiO}_{3}$ nanoparticles that were untreated was 37 and those treated in water, ethanol and xylene were 31,30 and 52 respectively. They concluded that the composites that were surface modified in xylene showed the most improved properties, reduced surface roughness and less voids compared with the non-surface treated composites. Huang et al. [47] investigated the influence of the surface modified $\mathrm{BaTiO}_{3}$ nanoparticles on the electrical, thermophysical and micromechanical properties of ethylene-vinyl acetate (EVM) vulcanizates. The nanoparticles were surface modified using gamma-aminopropyltriethoxysilane. The workers found that even at high concentrations ( $\sim 50 \%$ volume fraction) of $\mathrm{BaTiO}_{3}$, the filler powder uniformly dispersed within the matrix material, and attributed this to the substitution of hydroxyl groups on the $\mathrm{BaTiO}_{3}$ nanoparticles surface. They surmised that this process led to two effects: lowering of the interfacial tension between the separated phases and prevention of coalescence of the nanoparticles during processing. The dielectric constant of 50\% BT-EVM was 15 at $1 \mathrm{kHz}$. It was reported that the incorporation of surface modified $\mathrm{BaTiO}_{3}$ nanoparticles into the EVM matrix increased the permittivity, thermal conductivity (from $0.295 \mathrm{Wm}^{-1} \mathrm{~K}^{-1}$ for pure EVM matrix to $0.87 \mathrm{Wm}^{-1} \mathrm{~K}^{-1}$ for EVM-BaTiO $3(0.5)$ ). Similar to Iijima et al. [21], they attributed the higher dielectric strength of the nanocomposites at high $\mathrm{BaTiO}_{3}$ loading levels to the good dispersion state of $\mathrm{BaTiO}_{3}$ particles in EVM matrix and excellent interfacial adhesion between the polymer matrix and $\mathrm{BaTiO}_{3}$ nanoparticles [48,49]. Zeng et al. [50] fabricated bismaleimide-triazine resin/barium titanate $\left(\mathrm{BT} / \mathrm{BaTiO}_{3}\right)$ nanocomposite films, via a mix 
and cast approach, where the nanoparticles were surface treated using gamma-glycidoxypropyl trimethoxysilane (KH-560). It was reported that for the composite with $70 \mathrm{wt} . \%$ of $\mathrm{BaTiO}_{3}$, the effective dielectric constant at room temperature reached 23.63, and with a dielectric loss of 0.0212 at $100 \mathrm{~Hz}$. The dielectric properties of the nanocomposite films were nearly frequency-independent, which was attributed to the excellent dispersion of $\mathrm{BaTiO}_{3}$ nanoparticles in the $\mathrm{BT}$ matrix. The surface modification of $\mathrm{BaTiO}_{3}$ nanoparticles with silane coupling agent resulted in excellent dispersion and enhanced the interaction between $\mathrm{BaTiO}_{3}$ and the $\mathrm{BT}$ matrix.

Dalle Vacche et al. [51] investigated the influence of varying size $\mathrm{BaTiO}_{3}$ particles which were surface modified with aminopropyl triethoxy silane, and incorporated into poly (vinylidene fluoride-trifluoroethylene) $\mathrm{P}(\mathrm{VDF}-\mathrm{TrFE})$ up to $60 \%$ volume fraction. Three $\mathrm{BaTiO}_{3}$ powders were used $<2 \mu \mathrm{m}$ (average particle size $1.1 \mu \mathrm{m}$ ), $0.7 \mu \mathrm{m}$ and $0.2 \mu \mathrm{m}$. The dielectric permittivity for the composites containing $60 \%$ volume fraction of $\mathrm{BaTiO}_{3}$ was $\sim 113(1.1 \mu \mathrm{m})$ for surface treated and $\sim 100$ for non-surface treated composites and, $\sim 100(0.7 \mu \mathrm{m})$ for the surface treated samples and $\sim 80$ for the untreated samples and $\sim 85(0.2 \mu \mathrm{m})$ for the surface treated samples and $\sim 75$ for the untreated samples at $1 \mathrm{kHz}$, respectively. The dissipation factor was recorded to be $\sim 0.1$ for the untreated sample and $\sim 0.05$ for the surface treated samples. Surface modification was found to be effective for improving the dispersion of the ceramic in the matrix therefore reducing particle aggregates and enhancing the compatibility and adhesion of the P (VDF-TrFE) matrix to the inorganic filler. The composites also showed lower dielectric losses. Some workers have also illustrated a method for using point defects to explore the relationships between conduction loss/polarization and dielectric behaviour in semiconductor and graphitized carbon. [52]

In order to understand the role of interface in highly filled polymer nanocomposites due to a current lack of comprehensive research work Huang et al. [24] conducted the surface modification of $\mathrm{BaTiO}_{3}$ with 6 different types of surface chemistry was carried out. Epoxy resin (DGEBA) was used as the overlaying polymer matrix. Silane coupling agents (3-mercaptopropyltrimethoxysilane (KBM 803), 3-aminopropyltrimethoxysilane (KBM 903) and 2-(3,4-epoxycyclohexyl) ethyltrimethoxysilane (KBM 303) were used to surface modify $\mathrm{BaTiO}_{3}$ nanoparticles. All the nanocomposites contain $50 \mathrm{vol} \%$ $\mathrm{BaTiO}_{3}$ nanoparticles. The dielectric permittivity of pristine $\mathrm{BaTiO}_{3}, \mathrm{BaTiO}_{3}$ treated with $\mathrm{H}_{2} \mathrm{O}_{2}, \mathrm{BaTiO}_{3}$ treated with $\mathrm{KBM} 803, \mathrm{BaTiO}_{3}$ treated with $\mathrm{KBM} 903$ and $\mathrm{BaTiO}_{3}$ treated with $\mathrm{KBM} 303$ were found to be $30,31,25,28$ and 28 respectively at $1 \mathrm{kHz}$. They also reported that surface modification of $\mathrm{BaTiO}_{3}$ with silane coupling agents resulted in decreased dielectric loss tangent and weak dielectric dispersion. The majority of the existing literature does not provide insight regarding the influence of concentration of the coupling agent as a function of permittivity, both real and imaginary. As a result, there is a limited understanding on how the variability of the concentration of the coupling agent impacts the properties of the dielectric composite. This work aimed to understand how concentration of the coupling agent influences these parameters to develop an effective dielectric composite wherein, $\mathrm{BaTiO}_{3}$ /epoxy thick film composites were fabricated (volume fractions of $\mathrm{BaTiO}_{3}$ were varied from 0.10 to 0.60$)$. Nano-sized barium titanate $\left(\mathrm{BaTiO}_{3}\right)$ filler was surface modified using ethanol $(3 \mathrm{~mL}$ per unit gram of $\mathrm{BaTiO}_{3}$ ) and varying concentrations (in terms of volume fraction of the combined mixture) of silane coupling agent $(0.01,0.015,0.020$ and 0.025$)$.

\section{Materials and Methods}

\subsection{Materials}

The materials used in this work were $\mathrm{BaTiO}_{3}$ (Sigma-Aldrich, Saint louis, MO, USA, $<100 \mathrm{~nm}$ particle size, $\geq 99 \%$ ) in the cubic crystalline phase, Epofix Cold-Setting embedding resin (Bisphenol-A-Diglycidylether, Electron Microscopy Sciences, Hatfield, PA, USA) [53], Triethylenetetramine (epoxy hardener) and 3-Glycidyloxypropyltrimethoxysilane (Sigma-Aldrich, Saint louis, MO, USA, $\geq 98 \%$, KH-560). The dielectric and physical properties of the constituent materials: $\mathrm{BaTiO}_{3}$, DGEBA epoxy and $\mathrm{KH}-560$ are presented in Tables 1 and 2, respectively. 
Table 1. Physical properties of $\mathrm{BaTiO}_{3}$.

\begin{tabular}{cc}
\hline \multicolumn{2}{c}{ Barium Titanate Nano-Powder } \\
\hline Property & \\
\hline Density $\left(\mathrm{g} / \mathrm{cm}^{3}\right)$ & 6.08 \\
Mean Diameter & $\sim 100 \mathrm{~nm}$ \\
Curie Point $\left({ }^{\circ} \mathrm{C}\right)$ & $130{ }^{\circ} \mathrm{C}$ \\
Dielectric constant & $150[54]$ \\
$d_{33}(\mathrm{pC} / \mathrm{N})$ & $\sim 85.6$ (crystal)/ 191 (ceramic) \\
\hline & $*$ As received from manufacturer.
\end{tabular}

Table 2. Physical, dielectric and piezoelectric properties of DGEBA epoxy.

\begin{tabular}{lc}
\hline Property & \\
\hline Dielectric Constant & $2.9-3.0^{*}$ \\
Dielectric dissipation & $\sim 0.02-0.04$ \\
Electromechanical coupling factor, $k_{33}$ & - \\
Piezoelectric strain coefficient, $d_{33}$ & - \\
Density & $1.16 \mathrm{~g} / \mathrm{cm}^{3}$ \\
Electrical Resistivity & $0.15 @ 1 \mathrm{kHz}$ \\
\hline
\end{tabular}

${ }^{*}$ Experimental values.

\subsection{Experimental Method}

\subsubsection{Surface Modification of BTO with Ethanol}

The surface modification of the $\mathrm{BaTiO}_{3}$ (BTO) nano-powder using ethanol was used as the baseline datum for all studies, where it was used as a dispersant to aid in breaking down the particle-particle agglomerations [20]. The method for surface of modification using the ethanol and time study detailing the strategy for ascertaining agglomeration and dispersion of BTO using a Zeiss Sigma Field Emission scanning electron microscope (SEM, Oberkochen, Germany) and an Oxford INCA PentaFET x3 8100 energy dispersive X-ray spectroscopy (EDS, Oberkochen, Germany) is described in [55].

\subsubsection{Surface Modification of BTO with Silane Coupling Agent}

Glycidyloxypropyl type silane was chosen as the organic functional group in this work because glycidylfunctional epoxy resin i.e., dyglycidyl ether of bisphenol A (DGEBA) is the matrix material for the nanocomposites [50,56], this coupling agent is suitable for this type of matrix material. Four different volume fractions of coupling agent were used in this study: $0.01,0.015,0.020$ and 0.025 ( $v / v$ i.e., volume fraction percentage) to surface modify the $\mathrm{BaTiO}_{3}$ nano-powder using a process described by [55]. Subsequent sol gel synthesis and spin coat and film deposition processes were performed using the process describe in [55].

\subsubsection{Film Characterization}

The capacitance, resistance and conductance were measured using a Hewlett Packard 4194A Impedance/Gain-Phase Analyzer (Keysight Technologies, Santa Rosa, CA, USA) over a frequency between $2000 \mathrm{~Hz}$ and $40 \mathrm{MHz}$. This large frequency sweep provides insight into the electromechanical behavior of the sample with increasing frequency. The complex dielectric permittivity consists of the real and imaginary part. The real part of the complex permittivity is known as the dielectric constant and it is a measure of the charge storage abilities of the material. The imaginary part is the loss component i.e., dielectric loss or dissipation. This loss could originate from heat or from ohmic conduction of the material. The dielectric constant was calculated using Equation (1).

$$
\varepsilon_{r}=\frac{C t}{A \varepsilon_{0}}
$$


In Equation (1), $C, A, \varepsilon_{0}$ and $t$ are the capacitance in Farads, surface area of the sample, permittivity of free space $\sim 8.854 \times 10^{-12} \mathrm{~F} \mathrm{~m}^{-1}$, and thickness of the sample, respectively. The impedance, $Z$, was measured using a HP 4194A impedance analyzer. The real and imaginary parts of impedance, are resistance, $R$ and reactance, $X$, respectively as expressed in Equation (2).

$$
Z=R+j X
$$

The real part of impedance, i.e., resistance was then used to calculate resistivity, so as to normalize it for units of length as can be seen in Equation (3).

$$
\rho=\frac{R A}{t}
$$

Similarly, the admittance, $Y$, is also measured by the HP 4194A impedance analyzer which, like impedance, is also a complex quantity as shown in Equation (4).

$$
Y=G+j B
$$

where $G$ is conductance and $B$ is susceptance. Conductivity is calculated using Equation (5).

$$
\sigma=\frac{G t}{A}
$$

The effective permittivity of a polymer nanocomposite can be calculated by knowing the individual permittivity of the ceramic fillers and polymer matrix along with filler loading level i.e., volume fraction of the filler in the polymer matrix. There are several models that can be used to determine the effective permittivity of the composite.

The experimental values for the dielectric constant are compared to four theoretical models: (1) the Maxell-Garnett Equation, (2) the Bruggeman Self-Consistent Effective Medium Approximation, (3) the Lichtenker's Formula and (4) Jaysundere-Smith Equation. The Maxwell-Garnett model is typically applicable to composites composed of continuous media filled with spherical particles [57-59], where the polymer matrix is assumed as an isotropic medium with a dielectric permittivity $\varepsilon_{m}$ and the particles are assumed to be in the shape of spheroids with permittivity vales equal to $\varepsilon_{f}$. The volume fraction of filler particles, $\varnothing_{f}$, and the resulting volume fraction of the matrix is expressed as $\varnothing_{m}=1-\varnothing_{f}$. The aforementioned expression assumes the filler and matrix components have no dielectric loss and that the distance between the inclusions are greater than their characteristic sizes according to [60-64]. This model expressed in Equation (6) is not limited by the resistivity of the filler or the polymer matrix.

$$
\varepsilon_{e f f}=\varepsilon_{m}\left[1+\frac{3 \varnothing_{f}\left(\varepsilon_{f}-\varepsilon_{m}\right)}{\varnothing_{m}\left(\varepsilon_{f}-\varepsilon_{m}\right)+3 \varepsilon_{m}}\right]
$$

The Bruggeman Self-Consistent Effective Medium Approximation model is more applicable for composites that contain slightly larger filler concentrations in comparison to the Maxwell-Garnett equation (which is more effective for lower filler loadings). This model also yields better results when the fillers particles are very close to one another and even agglomerate $[57,64]$. The formula of this model for spherical fillers is expressed in Equation (7).

$$
\left(1-\varnothing_{f}\right) \frac{\varepsilon_{m}-\varepsilon_{e f f}}{\varepsilon_{m}+2 \varepsilon_{e f f}}+\varnothing_{f} \frac{\varepsilon_{m}-\varepsilon_{e f f}}{\varepsilon_{m}+2 \varepsilon_{e f f}}=0 .
$$


This can be further solved for the final Bruggeman's formula $[65,66]$, which is shown as Equation (8).

$$
\frac{\varepsilon_{f}-\varepsilon_{e f f}}{\varepsilon_{e f f}^{\frac{1}{3}}}=\frac{\left(1-\emptyset_{f}\right)\left(\varepsilon_{f}-\varepsilon_{m}\right)}{\varepsilon_{m}^{\frac{1}{3}}}
$$

This equation is expected to hold for $\varnothing_{f}$ values up to 0.5 , with the constraint that the dispersed spheres do not form a percolative path throughout the medium. On the other hand, the Lichtenker formula is a logarithmic mixture formula and is effective in calculating the permittivity of the polymer composite. The Lichtenecker's formula is shown in Equation (9) [67-69].

$$
\varepsilon_{e f f}^{\alpha}=\emptyset_{m} \varepsilon_{m}^{\alpha}+\emptyset_{f} \varepsilon_{f}^{\alpha}
$$

In Equation (9), $\varepsilon_{e f f}$ is the effective permittivity of the composite, and $\varepsilon_{m}$ and $\varepsilon_{f}$ are the permittivity values of the polymer matrix and ceramic filler, and $\emptyset_{f}$ and $\emptyset_{m}$ are the volume fraction of fillers and matrix, respectively. The parameter $\alpha$ varies from -1 to +1 and is considered to describe the transition from anisotropy $(\alpha=-1)$ to isotropy $(\alpha=+1)$ [57]. The Maxwell-Garnett equation is typically only valid for lower concentration of fillers since the interaction between filler particles is relatively weak, and at higher volume fractions the interaction between the fillers becomes significant because the distance between them reduces $[57,64]$. Jayasundere and Smith [70] proposed a more realistic mixing rule. They calculated the electric field with a dielectric sphere embedded in a continuous dielectric medium by taking into account polarization of adjacent particles and arrived at Equation (10).

$$
\varepsilon_{e f f}=\frac{\varnothing_{m} \varepsilon_{m}+\varnothing_{f} \varepsilon_{f} \frac{3 \varepsilon_{m}}{2 \varepsilon_{m}+\varepsilon_{f}}\left[1+3 \varnothing_{f} \frac{\left(\varepsilon_{f}-\varepsilon_{m}\right)}{2 \varepsilon_{m}+\varepsilon_{f}}\right]}{\varnothing_{m}+\varnothing_{f} \frac{3 \varepsilon_{m}}{2 \varepsilon_{m}+\varepsilon_{f}}\left[1+3 \varnothing_{f} \frac{\left(\varepsilon_{f}-\varepsilon_{m}\right)}{2 \varepsilon_{m}+\varepsilon_{f}}\right]}
$$

\section{Results and Discussion}

The Results and Discussion Section is divided into two subsections. The first subsection describes the dielectric permittivity of ethanol- and silane-surface treated samples, while the second subsection focuses on the conductivity samples.

\section{Dielectric Permittivity}

Dielectric Permittivity (BTO-Ethanol)

The $\mathrm{BaTiO}_{3}$-epoxy composites were fabricated using $\mathrm{BaTiO}_{3}$ nanoparticles that were surface modified using ethanol for $4 \mathrm{~h}$. The relative permittivity or dielectric constant was measured at $20 \mathrm{MHz}$ and plotted as function of increasing volume fraction of the nanoparticle fillers, as shown in Figure 2. In Figure 2, the relative permittivity is plotted as a function of volume fraction. In this figure, the permittivity increases as a function of volume fraction of the $\mathrm{BaTiO}_{3}$ filler. The ethanol is a dispersant in the composites, where it improves the dispersion of the filler. However, it does not act as a binding or molecular bridge between fillers and polymers [71-74].

Dielectric Permittivity (BTO-Silane Coupling Agent)

To observe the influence of the concentration of coupling agent on BTO nanoclusters, permittivity and dissipation spectra were obtained. The $\mathrm{BaTiO}_{3}$ nanoparticles were then surface modified using silane coupling agent, $\mathrm{KH}-560$ at a volume fraction of $0.01,0.015,0.020$ and 0.025 . The coupling agent enables more interfacial regions between $\mathrm{BaTiO}_{3}$ and epoxy creating a more uniform and homogeneous dispersion of nanoparticles within the matrix. The volume fraction of $\mathrm{BaTiO}_{3}$ for these composites was also varied from 0.1 through 0.6 . By varying the concentration of the coupling agent during surface 
treatment it enables us to gain a broader understanding of its interaction with $\mathrm{BaTiO}_{3}$ nanoparticles. The dielectric permittivity was measured using a HP 4194A impedance analyzer. These measurements were taken at a broad frequency range between $2000 \mathrm{~Hz}$ and $40 \mathrm{MHz}$. This enabled us to observe the behavior of the permittivity values with increasing frequency and to understand the effect or lack thereof of different polarization mechanisms. Here too, the $\mathrm{BaTiO}_{3}$ volume fraction was varied from 0.1 to 0.6 for each concentration of surface modification. All the composites were corona poled at $30 \mathrm{kV} / \mathrm{mm}$ to ensure consistency of data. Figure 2 shows the real part of permittivity of the untreated or pristine $\mathrm{BaTiO}_{3}$ /epoxy composites plotted against increasing frequency. As expected, one can see that the permittivity of the entire composite increases with increasing volume fraction of $\mathrm{BaTiO}_{3}$.

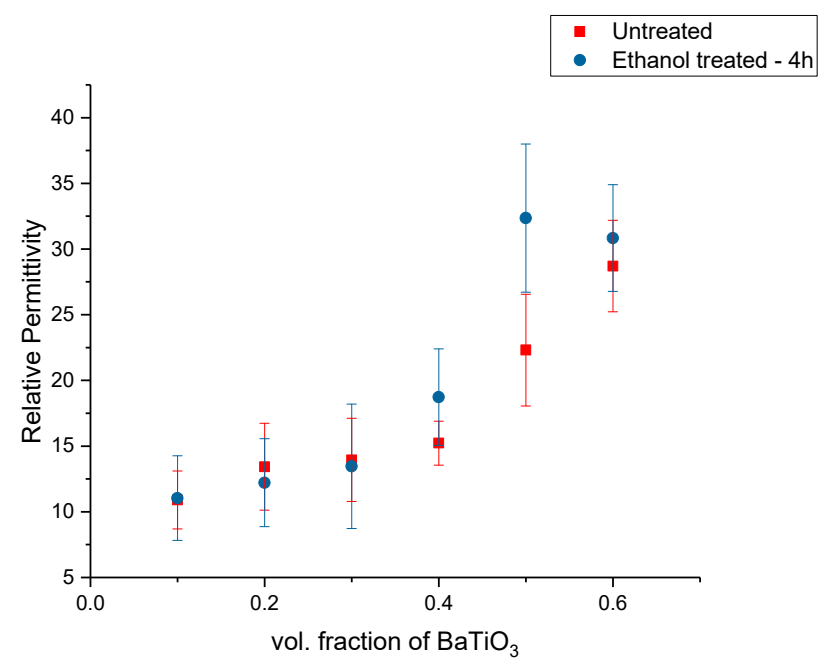

Figure 2. The relative permittivity of the $\mathrm{BaTiO}_{3}$-epoxy composite fabricated using $\mathrm{BaTiO}_{3}$ nanoparticles that were surface modified using ethanol for $4 \mathrm{~h}$ is plotted as a function of vol. fraction. The measurements were taken at $20 \mathrm{MHz}$.

The frequency dependence of permittivity shows a decrease in permittivity with increasing frequency for composites and resins [75]. The dielectric relaxations depicted in Figure 2, Figure 6, Figure 9, Figure 12 and Figure 17 can be explained by polarization mode changes. The polarization of dielectrics in alternating current fields has mode changes as frequency changes. Initially, at low frequencies, the total polarization manifests itself completely [12,76]. However, at high frequencies the internal space charges can no longer react (this is because the space charges cannot keep up with fast switching polarity of the electric field, i.e., the electric field switches rapidly and the space charges cannot react to it thereby negating its effect) and therefore, has no effect on the net polarization. Furthermore, the orientation of the polar groups is relatively slow and once the frequency increases, tends to lag behind. A further increase in frequency manifests in the inactivity of the dipole contributions towards polarization, i.e., only random orientations remain, and these do not contribute to the resultant polarization. Of the total polarization, now only the atomic and electronic polarization remain. At even further frequencies the stretching and bending of the bonds start to slacken, thereby negating the effect of the ionic polarization. Finally, at much higher frequencies $\sim 10^{15} \mathrm{~Hz}$ the distortion of electronic clouds from the nuclei begins to lag behind.

The real permittivity value at $20 \mathrm{MHz}$ attains a maximum value of 28.70 for the untreated $\mathrm{BaTiO}_{3} /$ epoxy composite where the volume fraction of $\mathrm{BaTiO}_{3}$ was $60 \%$ as shown in Figure 3 . The dissipation factor is defined as the ratio of imaginary part of permittivity i.e., dielectric loss with the real part of permittivity i.e., relative permittivity or dielectric constant. Therefore, the dielectric loss can be calculated my multiplying the dissipation factor and the relative permittivity. The maximum dissipation factor at $20 \mathrm{MHz}$ was recorded to be 0.3836 at a volume fraction of $60 \%$ of BaTiO which is comparable to that reported by Dalle Vacche et al. ( 0.4) [51]. It is important to note that the dissipation factor increases quite significantly at $60 \%$ of $\mathrm{BaTiO}_{3}$, as can be seen in Figure 5 and this could be 
attributed to the increase in agglomerations due to lack of wettability of the powders, and hence causing inhomogeneous dispersion of particles. This creates more air voids within the sample, increasing its porosity and making it difficult to pole, as the air voids are prone to increase in electric conduction.

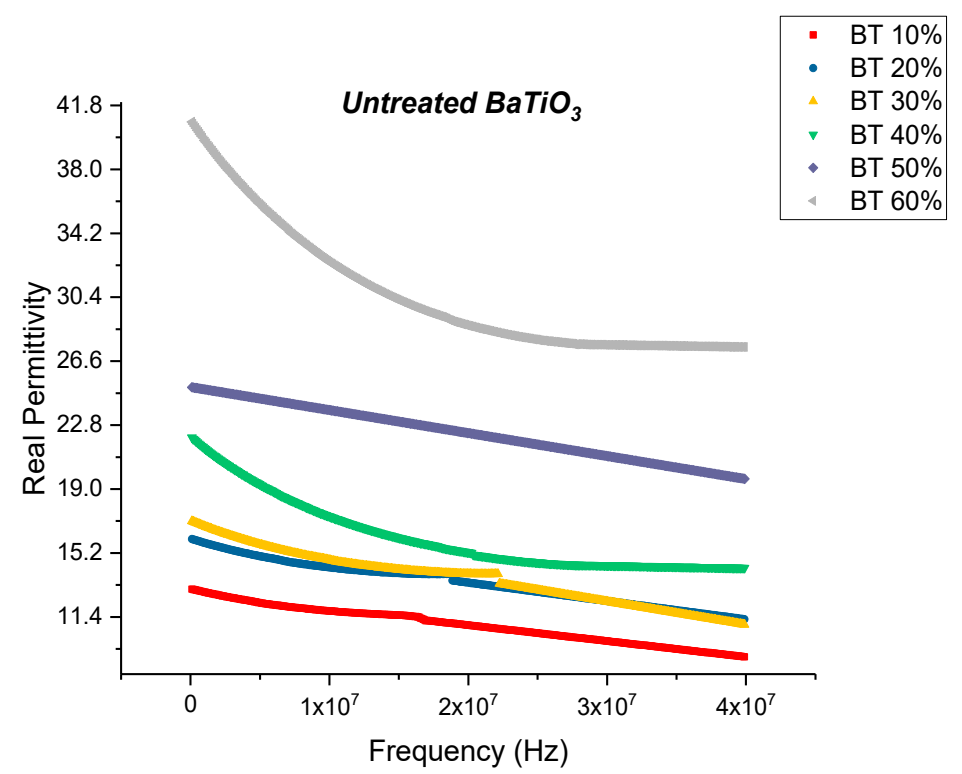

Figure 3. The real permittivity of the $\mathrm{BaTiO}_{3}$-epoxy composite that were fabricated using untreated $\mathrm{BaTiO}_{3}$ nanoparticles is plotted as a function of frequency where the volume fraction of $\mathrm{BaTiO}_{3}$ is varied from $10 \%$ to $60 \%$. This value at $20 \mathrm{MHz}$ attains a maximum of 28.70 at $60 \%$ volume fraction of $\mathrm{BaTiO}_{3}$.

The dielectric loss and dissipation factor for the composite that were prepared using untreated $\mathrm{BaTiO}_{3}$ nanoparticles are plotted as a function of increasing frequency as shown in Figures 4 and 5 , respectively, where the volume fraction of $\mathrm{BaTiO}_{3}$ was varied from 0.1 to 0.6. The maximum dielectric loss at $20 \mathrm{MHz}$ was recorded to be 11.06 at a volume fraction of 0.6 of $\mathrm{BaTiO}_{3}$.

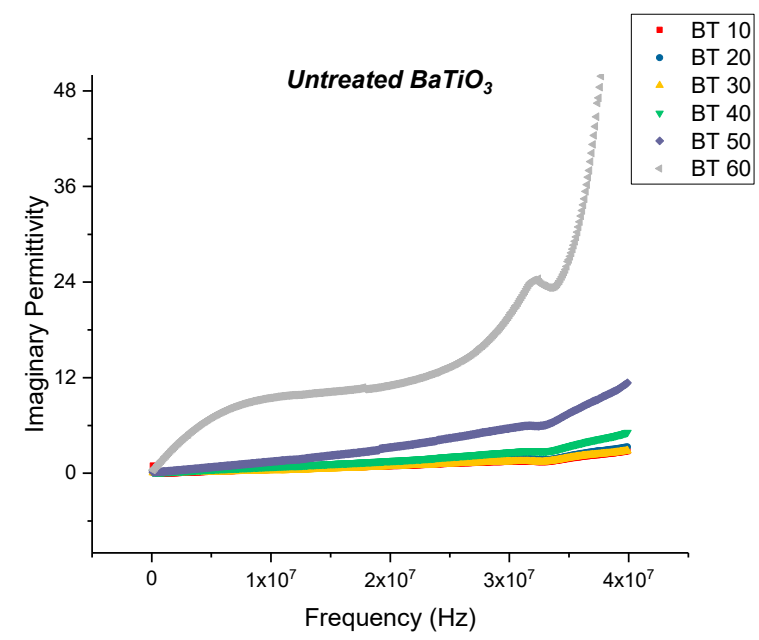

Figure 4. The dielectric loss of the $\mathrm{BaTiO}_{3}$-epoxy composite that were fabricated using untreated $\mathrm{BaTiO}_{3}$ nanoparticles is plotted as a function of frequency where the volume fraction of $\mathrm{BaTiO}_{3}$ is varied from 0.1 to 0.6 . The maximum dielectric loss at $20 \mathrm{MHz}$ was recorded to be 11.06 at a volume fraction of 0.6 of $\mathrm{BaTiO}_{3}$. 


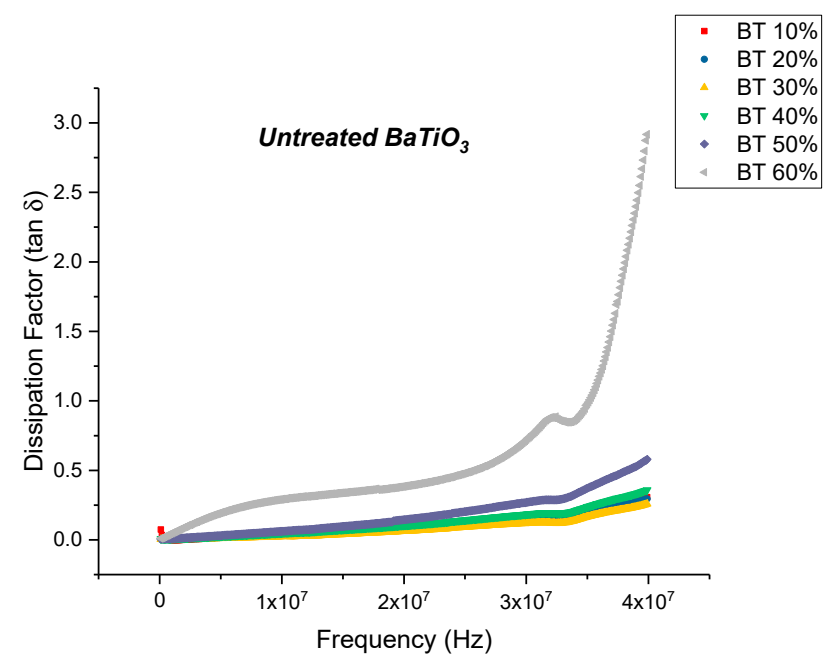

Figure 5. The dissipation factor of the $\mathrm{BaTiO}_{3}$-epoxy composite that were fabricated using untreated $\mathrm{BaTiO}_{3}$ nanoparticles is plotted as a function of frequency where the volume fraction of $\mathrm{BaTiO}_{3}$ is varied from 0.1 to 0.6 . The maximum dissipation factor at $20 \mathrm{MHz}$ was recorded to be 0.3836 at a volume fraction of 0.6 of $\mathrm{BaTiO}_{3}$.

The permittivity of the 0.01 surface treated samples also show an increase in value with increasing volume fraction of $\mathrm{BaTiO}_{3}$ as shown in Figure 6. The maximum value of real permittivity at $20 \mathrm{MHz}$ was recorded to be 32.80 at $60 \%$ volume fraction of $\mathrm{BaTiO}_{3}$. This is approximately $14.28 \%$ increase compared to the untreated samples. It was also found that at even high concentrations of $\mathrm{BaTiO}_{3}$ the composite did not crack or delaminate due to the improved dispersion, this observation has been made by several researchers $[13,21,24,47,50,77]$. With the addition of the coupling agent, a more homogeneous and uniform dispersion can be obtained. The enhanced dispensability of the nanoparticles can mainly be attributed to the substitution of the hydroxyl groups, which has a dual effect, (i) lowering interfacial tension between the separated phases and (ii) preventing coalescence of the nanoparticles during processing [47].

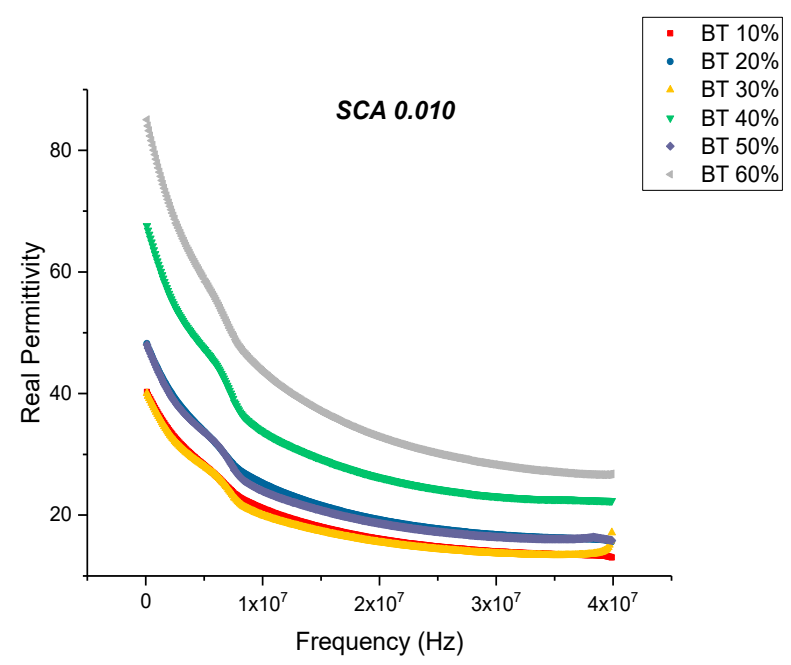

Figure 6. The real permittivity of the $\mathrm{BaTiO}_{3}$-epoxy composite that were fabricated using $\mathrm{BaTiO}_{3}$ nanoparticles which were surface modified using 0.010 SCA is plotted as a function of frequency where the volume fraction of $\mathrm{BaTiO}_{3}$ is varied from 0.1 to 0.6 .

From Figures 7 and 8, one can see that the dissipation factor and dielectric loss for the SCA 0.01 samples behaves similar to that of the untreated ones, wherein the dissipation factor begins to increase with increasing frequency. This is synonymous with the decrease in permittivity over the same 
frequency range. A relaxation process of the polymer matrix leads to a decrease in the permittivity values from low frequency to high frequency values. The dissipation factor at $20 \mathrm{MHz}$ attains a maximum value of 0.1106 , which is significantly lower compared to the untreated samples; 0.3836 . For composite systems, the dielectric loss factor might originate from the contributions of dipole orientation, conduction loss and interfacial polarization $[47,78]$. The loss factor could be expressed as a sum of three distinct effects [79] namely, conduction loss contribution, interfacial polarization and the dipole orientation or Debye loss factor. Surface treatment of the $\mathrm{BaTiO}_{3}$ nanoparticles minimizes the conduction losses due to substitution of the hydroxyl groups, which would have been present at the $\mathrm{BaTiO}_{3}$-epoxy interface.

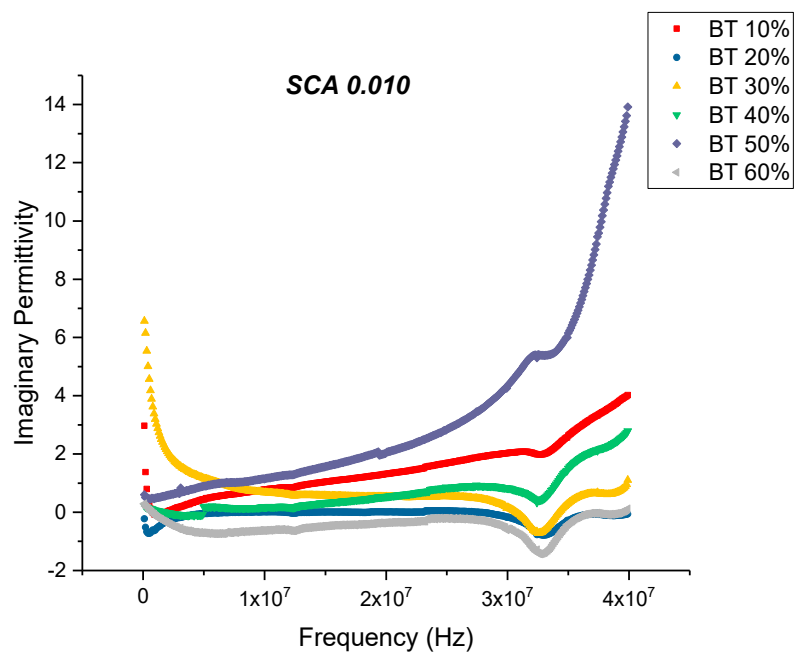

Figure 7. The dielectric loss of the $\mathrm{BaTiO}_{3}$-epoxy composite that were fabricated using $\mathrm{BaTiO}_{3}$ nanoparticles which were surface modified using 0.010 SCA is plotted as a function of frequency where the volume fraction of $\mathrm{BaTiO}_{3}$ is varied from 0.1 to 0.6 . The maximum value is 2.05 for $\mathrm{BaTiO}_{3}$ at 0.5 volume fraction. The imaginary permittivity increases with increasing volume fraction of $\mathrm{BaTiO}_{3}$ nanoparticles and increases with increasing frequency. With increasing frequency, there are fewer contributing factors to the real permittivity do the delayed response of these orientations.

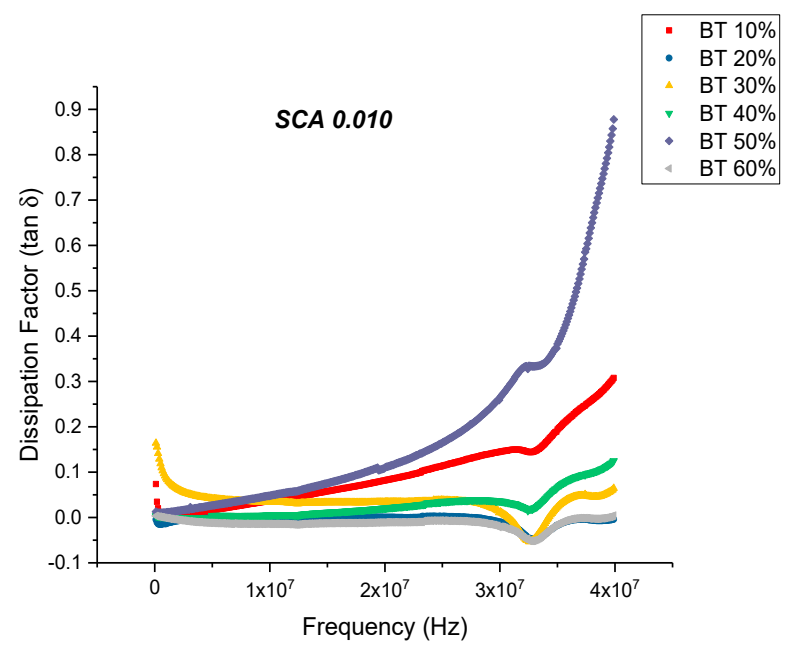

Figure 8. The dissipation factor of the $\mathrm{BaTiO}_{3}$-epoxy composite that were fabricated using $\mathrm{BaTiO}_{3}$ nanoparticles which were surface modified using 0.010 SCA is plotted as a function of frequency where the volume fraction of $\mathrm{BaTiO}_{3}$ is varied from 0.1 to 0.6 . The maximum value is 0.1106 for $\mathrm{BaTiO}_{3}$ at 0.5 volume fraction. 
For the samples that were surface treated using 0.015 concentration of silane coupling agent, the relative permittivity shows an increasing tendency with the loading levels of the nanoparticles as shown in Figure 9. The maximum permittivity values at $20 \mathrm{MHz}$ was found to be 41.76 at $50 \%$ volume fraction of $\mathrm{BaTiO}_{3}$. This value is a $27 \%$ increase compared to the permittivity of the SCA 0.015 sample. The loss factor begins to increase with increasing frequency and can be attributed to the decrease in reorientation of dipoles and polar entities, it may also originate from the contributions of conduction loss and interfacial polarization $[47,78]$.

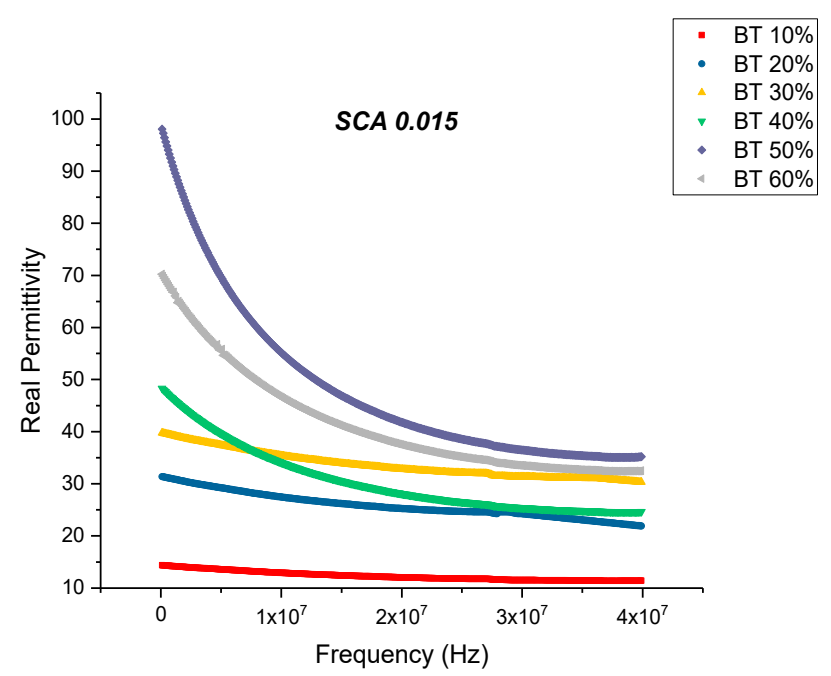

Figure 9. The real permittivity of the $\mathrm{BaTiO}_{3}$-epoxy composite that were fabricated using $\mathrm{BaTiO}_{3}$ nanoparticles which were surface modified using 0.015 SCA is plotted as a function of frequency where the volume fraction of $\mathrm{BaTiO}_{3}$ is varied from 0.1 to 0.6 .

The maximum dielectric loss and dissipation factor for $\mathrm{BaTiO}_{3} /$ epoxy composites prepared using SCA 0.015 occurs at $60 \%$ volume fraction of $\mathrm{BaTiO}_{3}$ as shown in Figures 10 and 11 . The trend observed for the dissipation factor shows an increase in value with increasing volume fraction of $\mathrm{BaTiO}_{3}$. This increase in dissipation factor can be attributed to the increased conduction losses associated with increasing amount of $\mathrm{BaTiO}_{3}$.

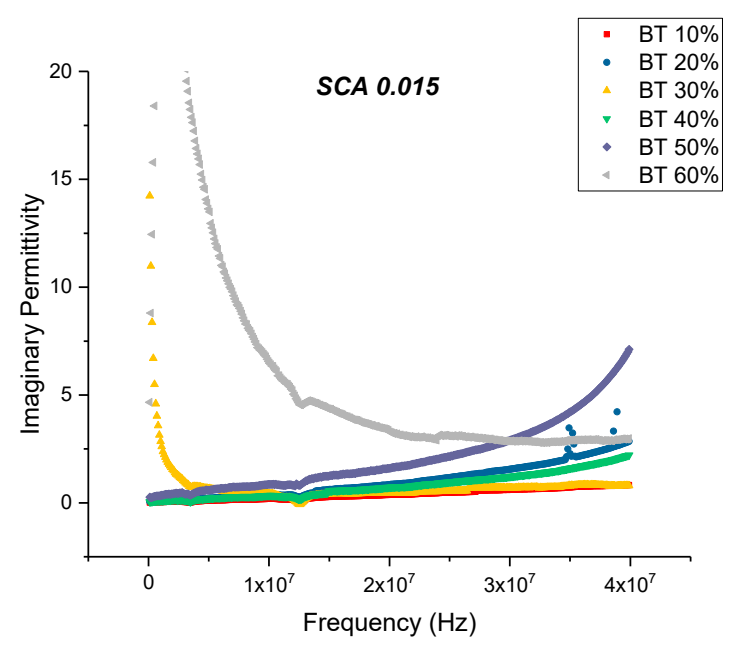

Figure 10. The dielectric loss of the $\mathrm{BaTiO}_{3}$-epoxy composite that were fabricated using $\mathrm{BaTiO}_{3}$ nanoparticles which were surface modified using 0.015 SCA is plotted as a function of frequency where the volume fraction of $\mathrm{BaTiO}_{3}$ is varied from 0.1 to 0.6 . The maximum value is 1.60 for $\mathrm{BaTiO}_{3}$ at 0.6 volume fraction. 


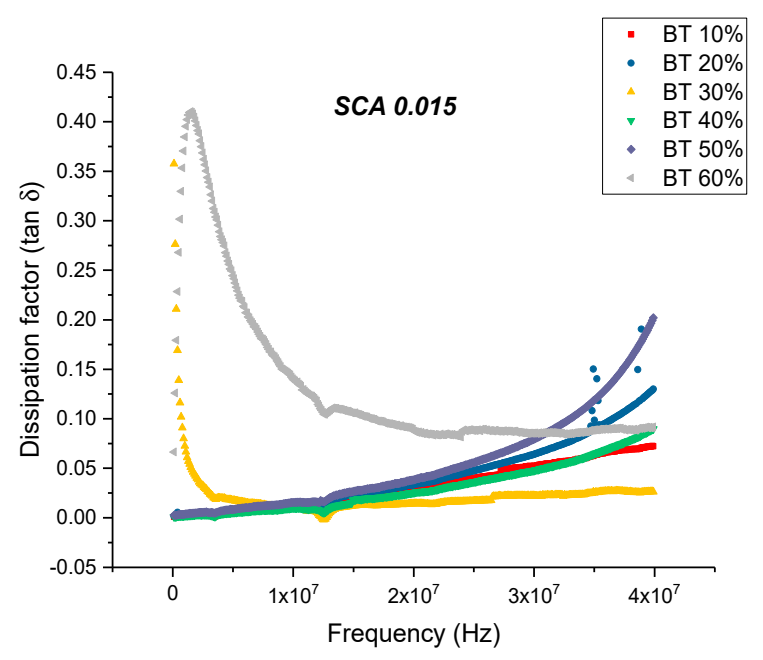

Figure 11. The dissipation factor of the $\mathrm{BaTiO}_{3}$-epoxy composite that were fabricated using $\mathrm{BaTiO}_{3}$ nanoparticles which were surface modified using 0.015 SCA is plotted as a function of frequency where the volume fraction of $\mathrm{BaTiO}_{3}$ is varied from 0.1 to 0.6 . The maximum value is 0.087 for $\mathrm{BaTiO}_{3}$ at 0.6 volume fraction. The imaginary permittivity increases with the increasing volume fraction of $\mathrm{BaTiO}_{3}$ nanoparticles and increases with increasing frequency. With increasing frequency, there are fewer contributing factors to the real permittivity do the delayed response of these orientations.

This is an almost $21 \%$ decrease in dissipation compared to the maximum value exhibited by the composites prepared using SCA 0.01. The decrease in dissipation factor, as previously mentioned, could be attributed to better interfacial bonding between the $\mathrm{BaTiO}_{3}$ nanoparticles and the epoxy matrix because the coupling agent acts as a molecular bridge between the two, and therefore, contributes to lower conduction losses [80,81].

There is a noticeable decrease in the real part permittivity as a function of frequency as shown in Figure 12, for BT with a 0.020 concentration of silane. The dielectric relaxations depicted in Figure 12 reflects polarization mode changes. There is a further decrease in dielectric loss and dissipation factor for the composite that were surface modified using SCA 0.020 as shown in Figures 13 and 14. For these composites prepared using 0.5 volume fraction of $\mathrm{BaTiO}_{3}$ the dissipation factor exhibits a value of 0.033 as shown in Figure 14 .

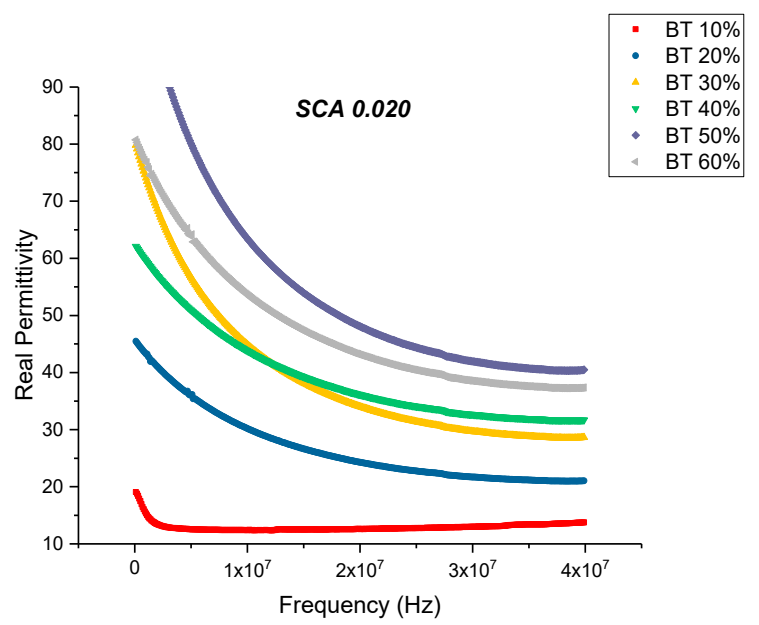

Figure 12. The real permittivity of the $\mathrm{BaTiO}_{3}$-epoxy composite that were fabricated using $\mathrm{BaTiO}_{3}$ nanoparticles which were surface modified using 0.020 SCA is plotted as a function of frequency where the volume fraction of $\mathrm{BaTiO}_{3}$ is varied from 0.1 to 0.6 . 


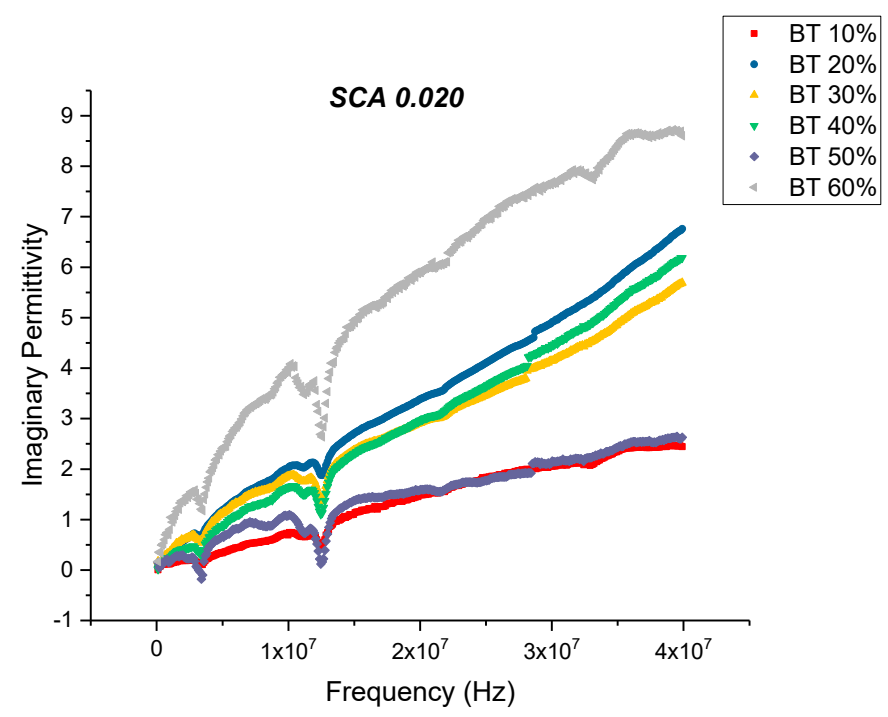

Figure 13. The dielectric loss of the $\mathrm{BaTiO}_{3}$-epoxy composite that were fabricated using $\mathrm{BaTiO}_{3}$ nanoparticles which were surface modified using 0.020 SCA is plotted as a function of frequency where the volume fraction of $\mathrm{BaTiO}_{3}$ is varied from 0.1 to 0.6 . The maximum value is 5.89 for $\mathrm{BaTiO}_{3}$ at 0.6 volume fraction.

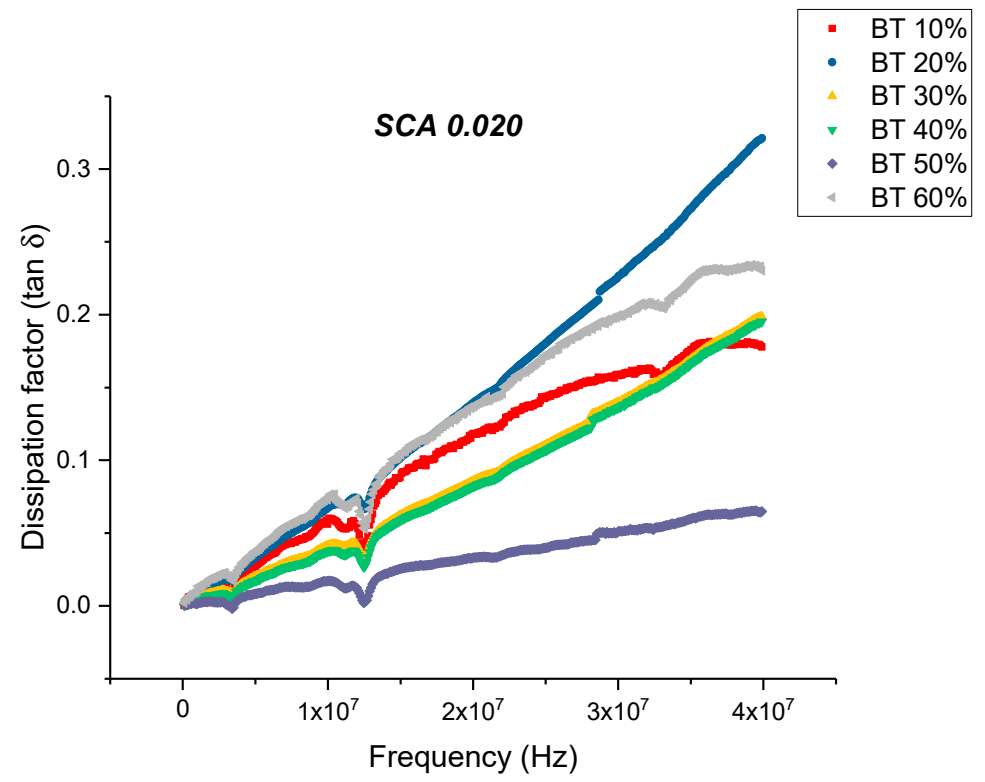

Figure 14. The dissipation factor of the $\mathrm{BaTiO}_{3}$-epoxy composite that were fabricated using $\mathrm{BaTiO}_{3}$ nanoparticles which were surface modified using 0.020 SCA is plotted as a function of frequency where the volume fraction of $\mathrm{BaTiO}_{3}$ is varied from 0.1 to 0.6 . The maximum value is 0.136 for $\mathrm{BaTiO}_{3}$ at 0.6 volume fraction.

When the concentration of coupling agent is increased to 0.025 and for higher $\mathrm{BaTiO}_{3}$ volume fractions, the dissipation factor began to increase again slowly as shown in Figure 15. From Figure 16, the maximum dissipation factor was found to be 0.119 at 0.6 volume fraction of $\mathrm{BaTiO}_{3}$. The concentration of silane coupling agent does not achieve as desirable of permittivity results for a concentration of 0.025 in comparison with the other concentrations of silane coupling agent as shown in Figure 17, which demonstrates further the importance of concentration of silane agent. 


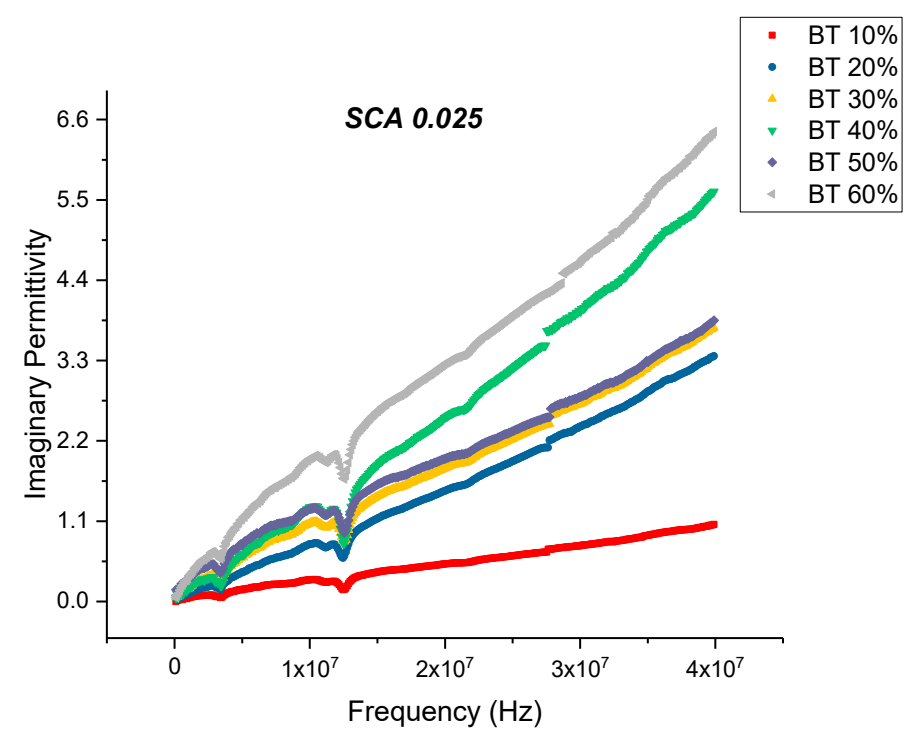

Figure 15. The dissipation factor of the $\mathrm{BaTiO}_{3}$-epoxy composite that were fabricated using $\mathrm{BaTiO}_{3}$ nanoparticles which were surface modified using 0.025 SCA is plotted as a function of frequency where the volume fraction of $\mathrm{BaTiO}_{3}$ is varied from 0.1 to 0.6 . The maximum value is 3.26 for $\mathrm{BaTiO}_{3}$ at 0.6 volume fraction.

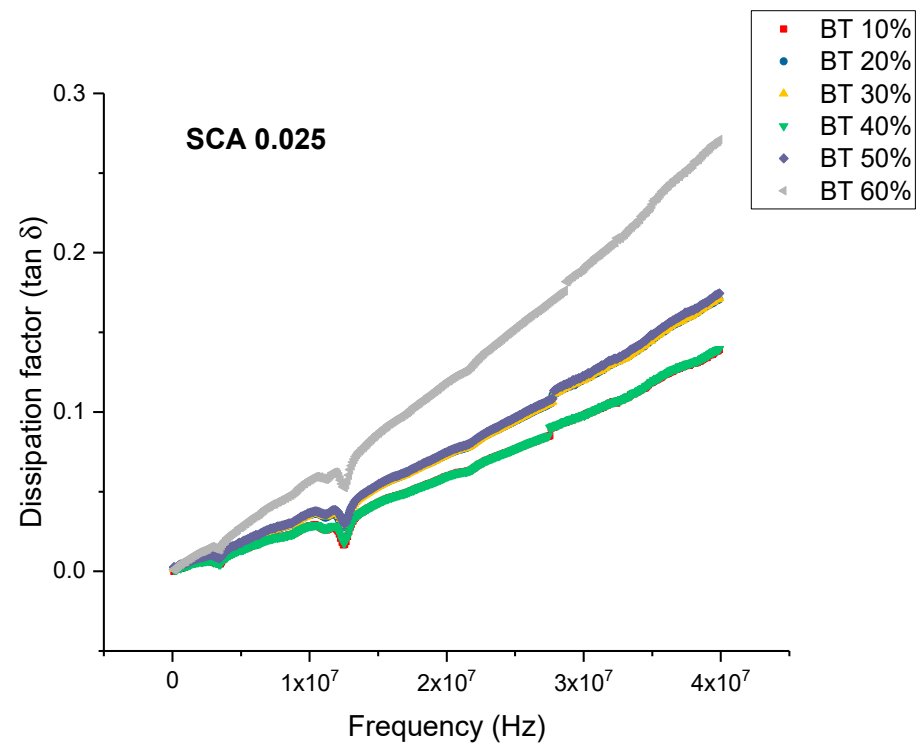

Figure 16. The dissipation factor of the $\mathrm{BaTiO}_{3}$-epoxy composite that were fabricated using $\mathrm{BaTiO}_{3}$ nanoparticles which were surface modified using $0.025 \mathrm{SCA}$ is plotted as a function of frequency where the volume fraction of $\mathrm{BaTiO}_{3}$ is varied from 0.1 to 0.6 . The maximum value is 0.119 for $\mathrm{BaTiO}_{3}$ at 0.6 volume fraction. 


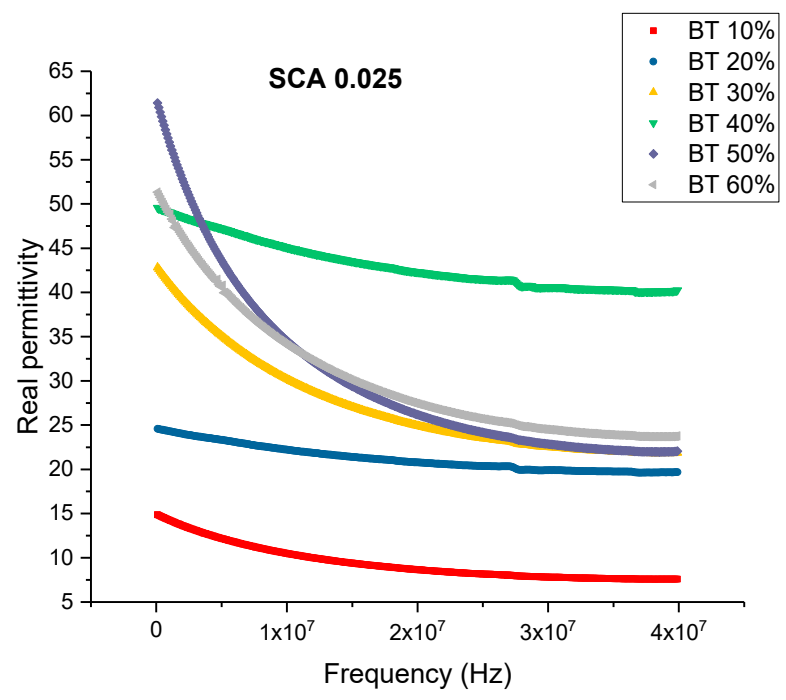

Figure 17. The real permittivity of the $\mathrm{BaTiO}_{3}$-epoxy composite that were fabricated using $\mathrm{BaTiO}_{3}$ nanoparticles which were surface modified using 0.025 SCA is plotted as a function of frequency where the volume fraction of $\mathrm{BaTiO}_{3}$ is varied from 0.1 to 0.6 .

A comparison of the experimental relative permittivity values and theoretical models is plotted in Figure 18. The mathematical models used were the Maxwell-Garnett equation, Bruggeman self-consistent effective medium approximation, the Jaysundere-Smith equation and Lichtenker rule. Table 3 lists the values of the values obtained from the mathematical models and the experimental values obtained at $20 \mathrm{MHz}$.

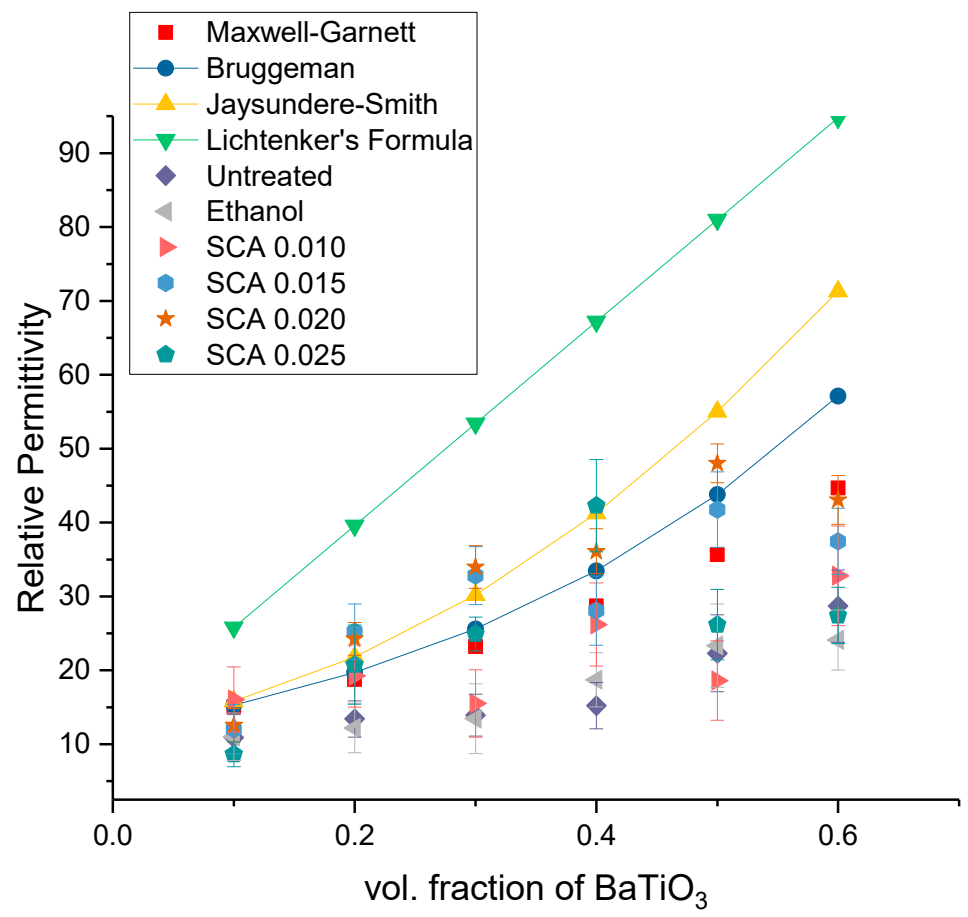

Figure 18. Comparison of the relative permittivity of the theoretical models with different experimental results, where the readings were taken at $20 \mathrm{MHz}$ for the composites that were prepared using 0.5 volume fraction of $\mathrm{BaTiO}_{3}$. 
Table 3. Comparison of the relative permittivity of the theoretical models with different experimental results, where the readings were taken at $20 \mathrm{MHz}$ for the composites that were prepared using 0.5 volume fraction of $\mathrm{BaTiO}_{3}$.

\begin{tabular}{cccc}
\hline Mymbol & Legend & Relative Permittivity & Standard Deviation \\
\hline & $\begin{array}{c}\text { Bruggeman Self-Consistent Effective } \\
\text { Medium Approximation }\end{array}$ & 35.65 & - \\
\hline Jaysundere-Smith Equation & 53.80 & - \\
\hline & Lichtenker's Formula & 85.02 & 5.2 \\
\hline & Entreated BaTiO 3 & 5.64 \\
\hline & Silane Coupling Agent-0.010 & 22.31 & 5.37 \\
\hline & Silane Coupling Agent-0.015 & 18.62 & 5.11 \\
\hline & Silane Coupling Agent-0.020 & 41.76 & 5.63 \\
\hline & Silane Coupling Agent-0.025 & 26.36 & 4.78 \\
\hline
\end{tabular}

A comparison of our work with the dielectric constants of other notable workers is presented in in Table 4, where our work demonstrates that optimization of surface treatment leads to enhanced properties by a factor of $\sim 1.5$ in comparison to our counterparts that employ non-piezoelectric matrix materials. It also demonstrates that optimization of surface treatment can lead to permittivity values that are very close to those that incorporate a piezoelectric-active matrix.

Table 4. Comparison of this work effort with other notable researchers who have fabricated state of the art materials.

\begin{tabular}{|c|c|c|}
\hline Type of Composite & Surface Modification & Dielectric Permittivity \\
\hline $\begin{array}{l}\mathrm{BaTiO}_{3} \text { - epoxy composite: thin } \\
\text { film capacitors [82] }\end{array}$ & $\begin{array}{c}\text { N-phenyl } \\
\text { aminopropyltrimethoxysilane }\end{array}$ & $40 @ 1 \mathrm{kHz}$ \\
\hline $\mathrm{BaTiO}_{3}$-epoxy composite $[83,84]$ & $\begin{array}{l}\text { 3-aminoprpoyltriethoxysilane } \\
\text { (KH-550) }\end{array}$ & vol. fraction $<70 \%$. $35 @ 10^{5} \mathrm{~Hz}$ \\
\hline $\mathrm{BaTiO}_{3} /$ epoxy composites $[85,86]$ & 3-glycidoxypropyltrimethoxysilane & $\sim 28 @ 10^{5} \mathrm{~Hz}$ \\
\hline $\begin{array}{l}\mathrm{BaTiO}_{3} /(\mathrm{EVM}) \text { copolymer } \\
\text { elastomer }[35,85]\end{array}$ & $\begin{array}{l}\gamma \text {-aminopropyl triethoxysilane } \\
\text { (Silquest A-1100) }\end{array}$ & $\begin{array}{l}\text { Increasing permittivity with } \mathrm{BaTiO}_{3} \\
\text { loading. 25@ } 70 \text { wt. } \% \text { of } \mathrm{BaTiO}_{3}\end{array}$ \\
\hline $\mathrm{BTresin} / \mathrm{BaTiO}_{3}[85,86]$ & $\begin{array}{l}\text { 3-glycidoxypropyl trimethoxysilane } \\
\text { (KH-560) }\end{array}$ & $\begin{array}{l}\text { Permittivity increased with loading. } \\
\sim 5 \text { at } 0 \%-\sim 25 \text { at } 70 \%\end{array}$ \\
\hline $\begin{array}{l}\mathrm{BaTiO}_{3} / \text { epoxy: Integral thin film } \\
\text { capacitors }[35,85]\end{array}$ & $\begin{array}{l}\text { N-phenyl } \\
\text { aminopropyltrimethoxysilane, } \\
\text { glycidoxy, mercapto, cyclohexyl }\end{array}$ & $\sim 40 @ 10^{5} \mathrm{~Hz}$ \\
\hline $\mathrm{BaTiO}_{3}$-epoxy composites [56] & Glycidoxymethoxysilane Z-6040 & $\begin{array}{l}\text { Increases with particles that were } \\
\text { surface modified } \sim 40 \text { at } 100 \mathrm{~Hz}\end{array}$ \\
\hline DGEBA-forsterite composites [85] & Aminopropyltriethoxy silane (APTS) & $\begin{array}{l}\text { Dielectric permittivity increased from } \\
3.7 \text { to } 3.9 \text { after surface treating. }\end{array}$ \\
\hline $\mathrm{BaTiO}_{3}-\mathrm{P}(\mathrm{VDF}-\mathrm{TrFE})[57]$ & 3-aminopropyltriethoxysilane (APTS) & $\begin{array}{l}\text { Dielectric permittivity improved-(i) } \\
100 \text { to } 113 \text {, (ii) } 80-100 \text { and (ii) } 75-85\end{array}$ \\
\hline $\mathrm{BaTiO}_{3}-\mathrm{DEGBA}$ epoxy (this work) & $\begin{array}{l}\gamma \text {-glycidyloxypropyltrimethoxysilane } \\
(\mathrm{KH}-560)\end{array}$ & $\begin{array}{l}76 @ 10 \mathrm{kHz}(0.20 \text { SCA }) \\
97 @ 100 \mathrm{~Hz}(0.150 \text { SCA }) \\
88 @ 1 \mathrm{kHz}(0.20 \text { SCA })\end{array}$ \\
\hline
\end{tabular}




\section{Conductivity (Untreated BTO and BTO-Silane Coupling Agent)}

The conductivity measurements, as expected, showed a similar trend to that of the resistivity observations as shown in Figures 19-23. For the composites prepared with 0.5 volume fraction of $\mathrm{BaTiO}_{3}$ and surface modified using SCA 0.015 , SCA 0.0 and SCA 0.025 the conductivity values were $2.61 \times 10^{-4} \mathrm{~S} / \mathrm{m}, 7.02 \times 10^{-5} \mathrm{~S} / \mathrm{m}$ and $7.3 \times 10^{-5} \mathrm{~S} / \mathrm{m}$, respectively.

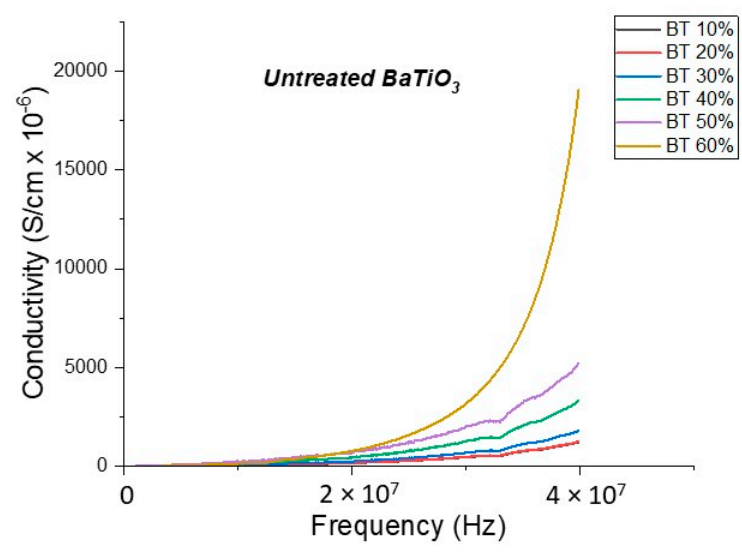

Figure 19. The conductivity of the $\mathrm{BaTiO}_{3}$-epoxy composite that were $\mathrm{BaTiO}_{3}$ nanoparticles which were not surface treated (pristine) is plotted as a function of frequency. The maximum value of conductivity at $20 \mathrm{MHz}$ is $7.84 \times 10^{-4} \mathrm{~S} / \mathrm{m}$ and occurs at BT 0.6.

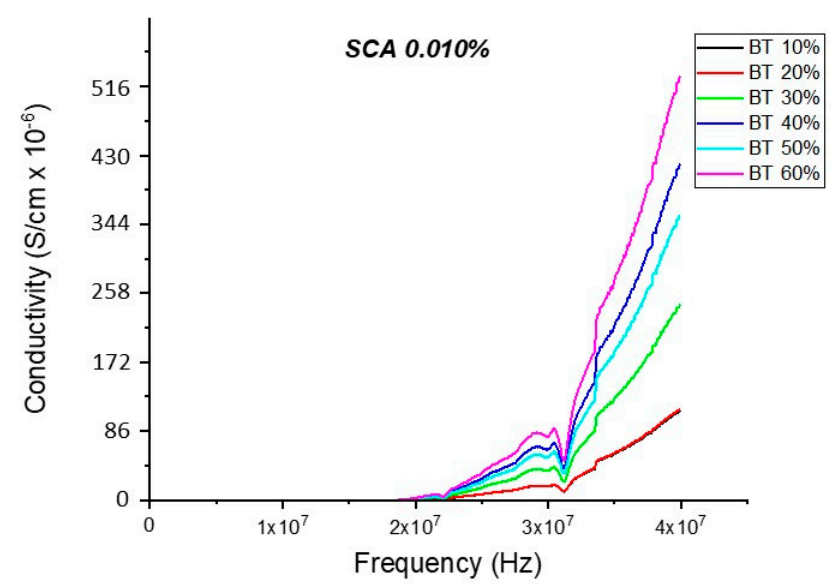

Figure 20. The conductivity of the $\mathrm{BaTiO}_{3}$-epoxy composite that were fabricated using $\mathrm{BaTiO}_{3}$ nanoparticles which were surface modified using 0.010 SCA is plotted as a function of frequency. The maximum value of conductivity at $20 \mathrm{MHz}$ is $4.63 \times 10^{-4} \mathrm{~S} / \mathrm{m}$ and occurs at BT 0.6. 


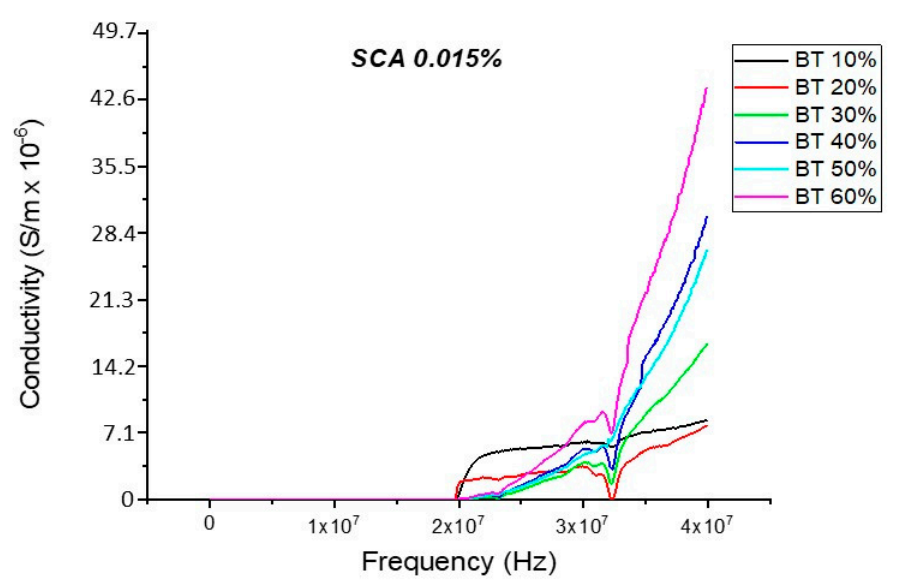

Figure 21. The conductivity of the $\mathrm{BaTiO}_{3}$-epoxy composite that were fabricated using $\mathrm{BaTiO}_{3}$ nanoparticles which were surface modified using 0.015 SCA is plotted as a function of frequency. The maximum value of conductivity at $20 \mathrm{MHz}$ is $4.36 \times 10^{-4} \mathrm{~S} / \mathrm{m}$ and occurs at BT 0.6.

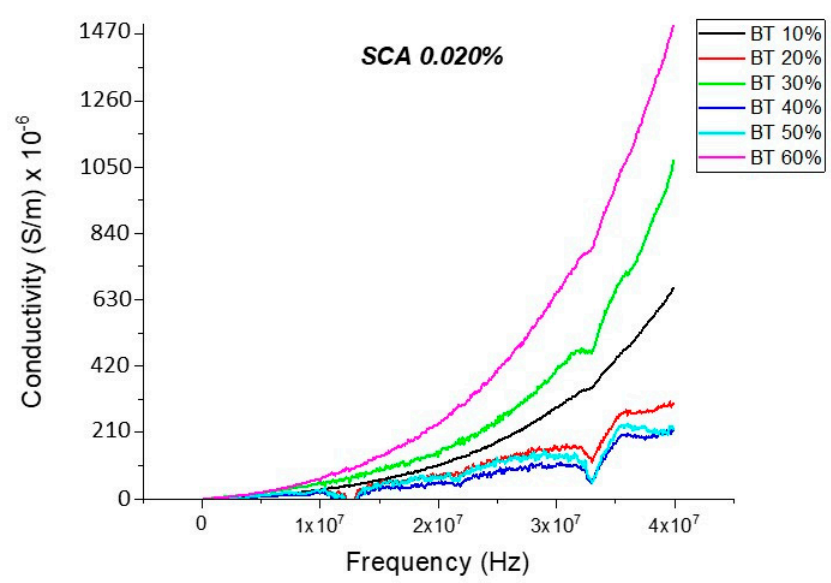

Figure 22. The conductivity of the $\mathrm{BaTiO}_{3}$-epoxy composite that were fabricated using $\mathrm{BaTiO}_{3}$ nanoparticles which were surface modified using 0.020 SCA is plotted as a function of frequency. The maximum value of conductivity at $20 \mathrm{MHz}$ is $2.38 \times 10^{-4} \mathrm{~S} / \mathrm{m}$ and occurs at BT 0.6 .

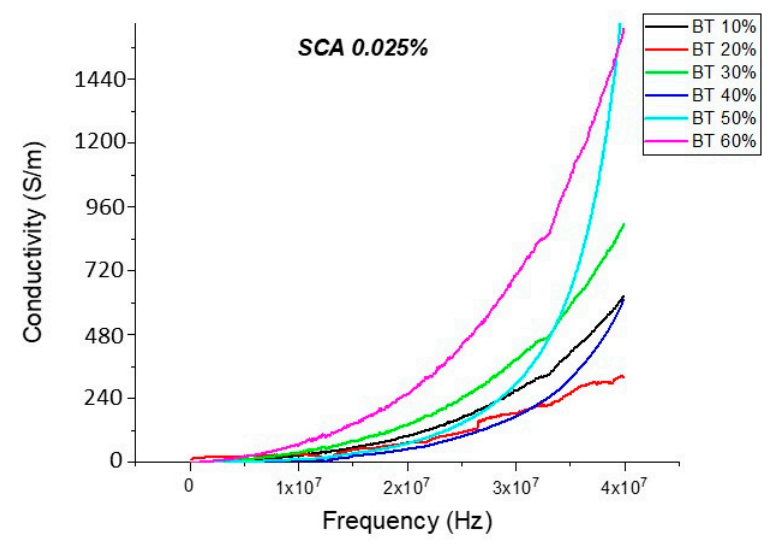

Figure 23. The conductivity of the $\mathrm{BaTiO}_{3}$-epoxy composite that were fabricated using $\mathrm{BaTiO}_{3}$ nanoparticles which were surface modified using 0.025 SCA is plotted as a function of frequency. The maximum value of conductivity at $20 \mathrm{MHz}$ is $2.58 \times 10^{-4} \mathrm{~S} / \mathrm{m}$ and occurs at BT 0.6.

There is a decrease in conductivity of the SCA 0.015 and SCA 0.020 surface treated samples by $\sim 73 \% 20 \mathrm{MHz}$ in $50 \% \mathrm{BaTiO}_{3}$ samples as shown in Figures 21-23. Moreover, the conductivity of the composites decreases as a function of silane coupling agent volume fraction. The pristine or untreated 
$\mathrm{BaTiO}_{3}$ tends to adsorb water onto its surface due to its hydrophilic nature $[13,14]$. The silane coupling surface modification leads to the substitution of the hydroxyl $(-\mathrm{OH}-)$ groups on the surface of the $\mathrm{BaTiO}_{3}$ filler that has a modified surface chemistry of $(\mathrm{O}-\mathrm{Si}-)$ as shown in Figure 24 . As indicated in the FTIR plot in Figure 24, as the concentration of coupling agent increases, more reactions may occur, which lead to the reduction in electrical conductivity [21,77].
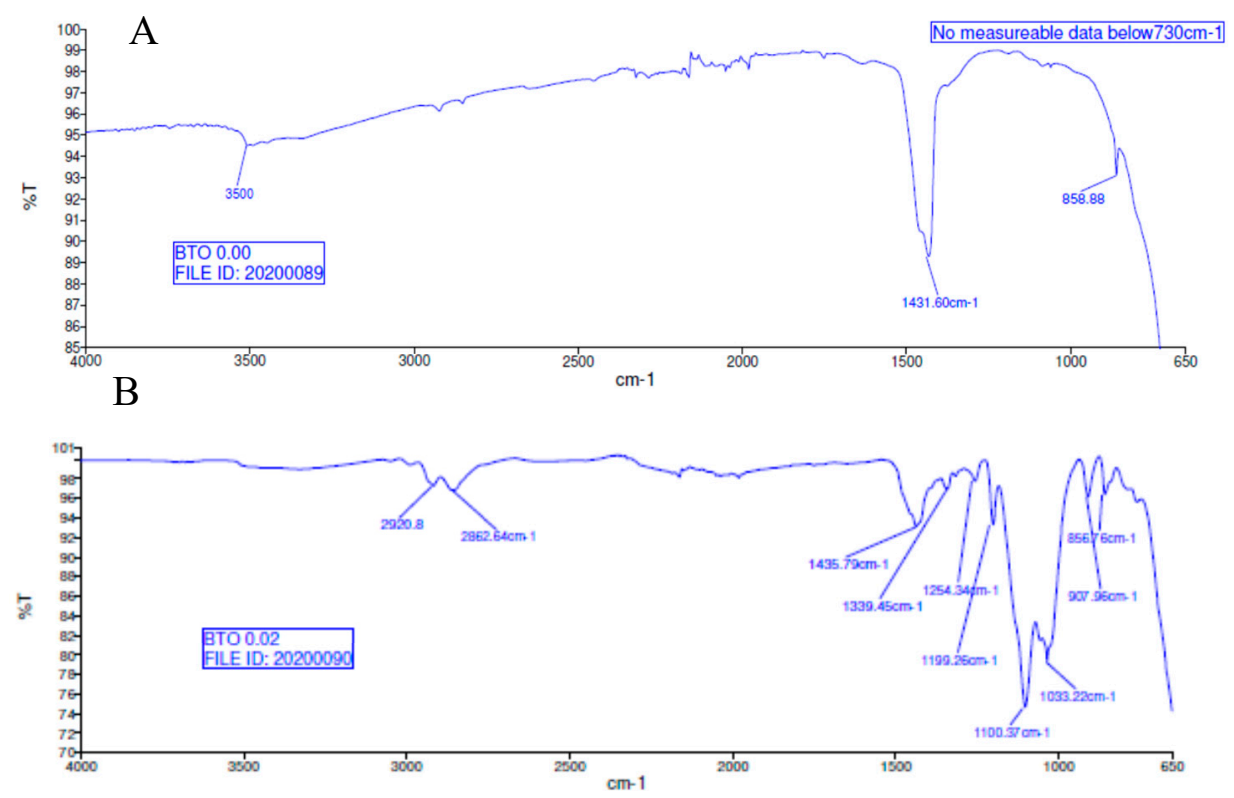

Figure 24. FTIR spectra of (A) BTO and (B) surface modified BTO particles.

In Figure 24, Fourier-transform infrared spectroscopy (FTIR) of the BTO powder (A) and surface treated BTO powder (B) are presented. The reaction mechanism leading to enhance dielectric permittivity is due to the coupling agent and modified surface of the BTO whose interfacial bond with the epoxy matrix is enhanced by way of the addition of the silane coupling agent as indicated in Figure 25. The bands at $1435-1390 \mathrm{~cm}^{-1}$ represent BTO, while the broad peak centered at $3500 \mathrm{~cm}^{-1}$ is attributed to hydroxyl groups on the BTO nanoparticles which are present in the as-made BTO. The bands between $850-900$ represent the $\mathrm{Si}-\mathrm{O}(\mathrm{Si}-\mathrm{OH})$ stretching vibration band groups, while the range from $2850-2950 \mathrm{~cm}^{-1}$ represents the $\mathrm{CH}$ and $\mathrm{CH}_{2}$ stretching aliphatic group, detailed in Table 5 . The silane coupling agent, $\mathrm{KH}-560$, contains an organic functional group that resembles an epoxy chain and three alkoxide groups viz. $\left(\mathrm{Si}-\mathrm{OCH}_{3}\right)$. During the surface modification procedure, which involves mixing $\mathrm{KH}-560$, ethanol and $\mathrm{BaTiO}_{3}$, the alkoxide groups are hydrolyzed by water generating $\mathrm{Si}-\mathrm{OH}$ groups and alcohols, as can be seen in Figures 25 and 26. The water that reacts with the alkoxide groups can come from two sources namely, (i) the solvent, in this case ethanol (95/5; ethanol/water) or (ii) water adsorbed on particle surface when an anhydrous solvent is used.

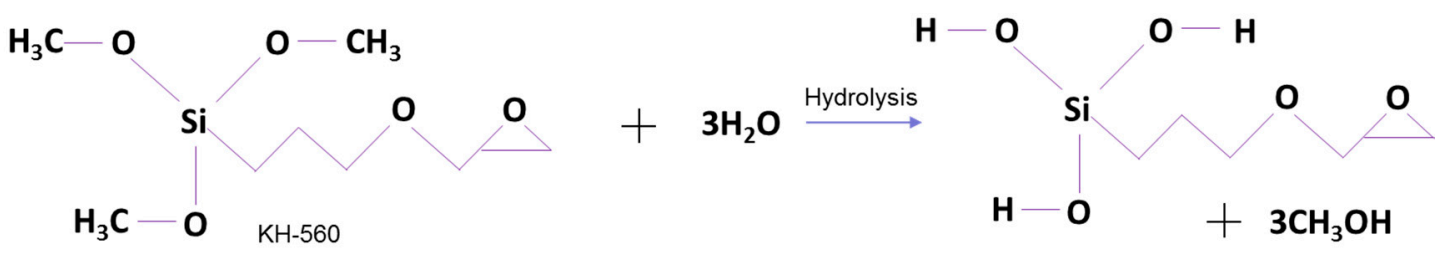

Figure 25. The alkoxide groups $\left(\mathrm{Si}-\mathrm{OCH}_{3}\right)$ of $\mathrm{KH}-560$ are hydrolyzed by water thereby leading to the formation of $\mathrm{Si}-\mathrm{OH}$ groups and methanol. 
Table 5. Wavelength $\left(\mathrm{cm}^{-1}\right)$ and bond type found in silane films.

\begin{tabular}{cc}
\hline Wavelength $\left(\mathbf{c m}^{\mathbf{- 1}}\right)$ & Bond Type \\
\hline $700-800$ & $\mathrm{C}-\mathrm{H}\left(\mathrm{Si}-\mathrm{CH}_{2}-\mathrm{CH}_{2}-\mathrm{Si}\right)$ stretching vibrations \\
$850-900$ & $\mathrm{Si}-\mathrm{O}(\mathrm{Si}-\mathrm{OH})$ stretching vibrations \\
$900-960$ & $\mathrm{Si}-\mathrm{O}-\mathrm{C}_{2} \mathrm{H}_{5}$ vibrations \\
$1000-1250$ & $\mathrm{Si}-\mathrm{O}$ (from $\mathrm{Si}-\mathrm{O}-\mathrm{Si}$ bonds) vibrations \\
$1300-1400$ & $\mathrm{CH}_{2}$ and $\mathrm{CH}_{3}$ bending vibrations \\
$3200-3700$ & $\mathrm{OH}$ (from $\mathrm{Si}-\mathrm{OH}$ group) stretching vibrations \\
\hline
\end{tabular}<smiles></smiles>

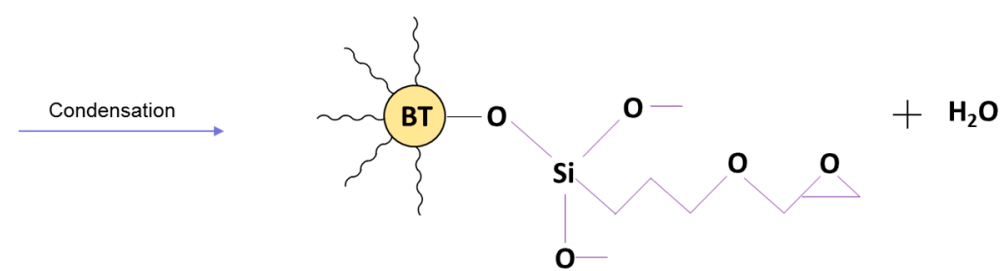

Figure 26. A condensation reaction occurs between the newly formed $\mathrm{Si}-\mathrm{OH}$ groups of the coupling agent and the hydroxyl groups adsorbed on the surface of the $\mathrm{BaTiO}_{3}$ nanoparticle.

The hydrolysis reaction is followed by a condensation reaction between the newly formed $\mathrm{Si}-\mathrm{OH}$ groups of the coupling agent and the hydroxyl groups on the surface of the $\mathrm{BaTiO}_{3}$ nanoparticle, as shown in Figure 26. This causes $\mathrm{BaTiO}_{3}$ to rid itself of the hydroxyl group on its surface with a coupling agent that can bond easily with epoxy as can be seen in Figure 27. The condensation reaction leads to the formation of water and $\mathrm{BaTiO}_{3}$ particles with a modified surface chemistry. This reaction makes the BT nanoparticle surface more compatible with the epoxy matrix.

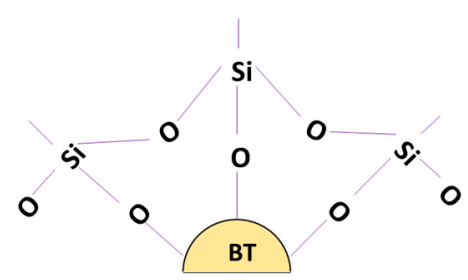

Figure 27. The surface of the $\mathrm{BaTiO}_{3}$ nanoparticle, which previously contained hydroxyl groups now is replaced by a coupling agent which can bond easily with epoxy resin.

If multiple such reactions occur, then more hydroxyl groups are available to react with the coupling agent, leading to the formation a modified $\mathrm{BaTiO}_{3}$ particle as shown in Figure 27.

The results above indicate that for a single particle surface the hydroxyl (-OH-) groups have been substituted with that of the coupling agent after the condensation of the silanol groups. This implies that the $\mathrm{BaTiO}_{3}$ can bond easily with the epoxy (Bisphenol A diglycidyl ether) matrix due to the 'glycidyl' functional group of the coupling agent ( $\mathrm{y}$-glycidyloxytrimethoxysilane).

\section{Conclusions}

Silicon molecules that were adsorbed onto the surface of the $\mathrm{BaTiO}_{3}$ nanoparticle were observed using the EDS micrograph images, which also showed the reduction in the aggregate size, which led to better particle distribution. The highest value of permittivity $(\sim 48.03)$ and the lowest value of loss 
( $~ 0.136)$ were observed for the samples that were fabricated using 0.5 volume fraction of $\mathrm{BaTiO}_{3}$ and that were surface treated with 0.02 volume fraction of silane coupling agent. The improved adhesion between the polymer-ceramic interface led to higher interfacial polarization within the composite material and resulted in increased permittivity values. Due to the insulating adsorption layer of the organofunctional silane the localized conductivity at the interface was reduced leading to enhanced permittivity values.

Author Contributions: The co-authors worked together to produce this manuscript. The contribution of each co-author is described herein. Conceptualization of the ideas and establishment of the experimental method were originated through discussions between K.C.-C. and U.S. Samples were prepared and characterized by co-authors U.S. and Z.L. All authors have read and agreed to the published version of the manuscript.

Funding: This research was funded by the National Science Foundation, grant number 1263250 and 1659818.

Conflicts of Interest: The authors declare no conflict of interest. The funders had no role in the design of the study; in the collection, analyses, or interpretation of data; in the writing of the manuscript, or in the decision to publish the results.

\section{References}

1. Herbert, J. Ceramic Dielectrics and Capacitors, Electrocomponent Science Monographs; Gordon and Breach Science Publishers: New York, NY, USA, 1985; Volume 6.

2. Mizukoshi, T. Capacitor Market in Japan: Key Research Findings 2009. Available online: https://www. yanoresearch.com/press/pdf/554.pdf (accessed on 21 March 2020).

3. Zou, K.; Dan, Y.; Xu, H.; Zhang, Q.; Lu, Y.; Huang, H.; He, Y. Recent advances in lead-free dielectric materials for energy storage. Mater. Res. Bull. 2019, 113, 190-201. [CrossRef]

4. Qiao, Y.; Li, W.; Zhang, Y.; Jing, L.; Yang, X.; Gao, C.; Cao, W.; Fei, W. Ba and Mg co-doping to suppress high-temperature dielectric loss in lead-free $\mathrm{Na}_{0.5} \mathrm{Bi}_{0.5} \mathrm{TiO}_{3}$-based systems. J. Eur. Ceram. Soc. 2020, 40, 720-727. [CrossRef]

5. Xiao, M.; Zhang, P.; Lou, J.; Wei, Y.; Zhang, P. Combined synthesis methods for producing LaNbO4 ceramics and investigation of microwave dielectric properties based on complex chemical bond theory. J. Alloys Compd. 2020, 812, 152154. [CrossRef]

6. Yu, K.; Hu, S.; Tan, J.; Yu, W. Dielectric and piezoelectric properties of $\left(\mathrm{K}_{0.475} \mathrm{Na}_{0.495} \mathrm{Li}_{0.03}\right)$ $\mathrm{NbO}_{3}-0.003 \mathrm{ZrO}_{2} / \mathrm{PVDF}$ 0-3 composite reinforced with two types of nano-ZnO particles. J. Mater. Sci. 2020, 31, 1367-1381.

7. Zhao, Q.; Zhang, H.W.; Li, J.; Xu, F.; Liao, Y.; Liu, C.; Su, H. Low-temperature sintering synthesis and electromagnetic properties of $\mathrm{NiCuZn} / \mathrm{BaTiO}_{3}$ composite materials. J. Alloys Compd. 2019, 788, 44-49. [CrossRef]

8. Chen, Y.; Ye, H.H.; Wang, X.S.; Li, Y.; Yao, X. Grain size effects on the electric and mechanical properties of submicro $\mathrm{BaTiO}_{3}$ ceramics. J. Eur. Ceram. Soc. 2020, 40, 391-400. [CrossRef]

9. Hussain, A.; Sinha, N.; Joseph, A.J.; Goel, S.; Singh, B.; Bdikin, I.; Kumar, B. Mechanical investigations on piezo-/ferrolectric maleic acid-doped triglycine sulphate single crystal using nanoindentation technique. Arab. J. Chem. 2020, 13, 1874-1889. [CrossRef]

10. Nasrin, S.; Khan, S.M.; Matin, M.A.; Khan, M.N.I; Hossain, A.A.; Rahaman, M.D. Synthesis and deciphering the effects of sintering temperature on structural, elastic, dielectric, electric and magnetic properties of magnetic $\mathrm{Ni}_{0.25} \mathrm{Cu}_{0.13} \mathrm{Zn}_{0.62} \mathrm{Fe}_{2} \mathrm{O}_{4}$ ceramics. J. Mater. Sci. 2019, 30, 10722-10741. [CrossRef]

11. Reznichenko, A.N.; Lugovaya, M.A.; Petrova, E.I.; Shvetsova, N.A.; Rybyanets, A.N. Lead-free porous and composite materials for ultrasonic transducers applications. Ferroelectrics 2019, 539, 93-100. [CrossRef]

12. Hyun, J.-G.; Paik, K.-W.; Pak, J.S. Characterization of Epoxy/BaTiO ${ }_{3}$ Composite Embedded Capacitors for High Frequency Behaviors. In Proceedings of the 59th Electronic Components and Technology Conference, San Diego, CA, USA, 26-29 May 2009.

13. Liang, S.; Chong, S.R.; Giannelis, E.P. Barium Titanate/Epoxy Composite Dielectric Materials for Integrated Thin Film Capacitors. In Proceedings of the 48th Electronic Components and Technology Conference, Seattle, WA, USA, 25-28 May 1998. 
14. Ramesh, S.; Huang, C.; Liang, S.; Giannelis, E.P. Integrated Thin Film Capacitors: Interfacial Control and Implications on Fabrication and Performance. In Proceedings of the 49th Electronic Components and Technology Conference, San Diego, CA, USA, 1-4 June 1999.

15. Pan, M.-J.; Randall, C.A. A brief introduction to ceramic capacitors. IEEE Electr. Insul. Mag. 2010, 26, 44-50. [CrossRef]

16. Arbatti, M.; Shan, X.; Cheng, Z.Y. Ceramic-polymer composites with high dielectric constant. Adv. Mater. 2007, 19, 1369-1372. [CrossRef]

17. Avila, H.; Ramajo, L.; Góes, M.; Reboredo, M.M.; Castro, M.S.; Parra, R. Dielectric behavior of epoxy/BaTiO 3 composites using nanostructured ceramic fibers obtained by electrospinning. ACS Appl. Mater. Interfaces 2013, 5, 505-510. [CrossRef] [PubMed]

18. Bai, W.; Zheng, P.; Wen, F.; Zhang, J.; Chen, D.; Zhai, J.; Ji, Z. Lead-free BNT-based composite materials: Enhanced depolarization temperature and electromechanical behavior. Dalton Trans. 2017, 46, 15340-15353. [CrossRef] [PubMed]

19. Bai, Y.; Cheng, Z.-Y.; Bharti, V.; Xu, H.S.; Zhang, Q.M. High-dielectric-constant ceramic-powder polymer composites. Appl. Phys. Lett. 2000, 76, 3804-3806. [CrossRef]

20. Sundar, U.; Cook-Chennault, K.A.; Banerjee, S.; Refour, E. Dielectric and piezoelectric properties of percolative three-phase piezoelectric polymer composites. J. Vac. Sci. Technol. B 2016, 34, 041232. [CrossRef]

21. Iijima, M.; Sato, N.; Lenggoro, I.W.; Kamiya, H. Surface modification of $\mathrm{BaTiO}_{3}$ particles by silane coupling agents in different solvents and their effect on dielectric properties of $\mathrm{BaTiO}_{3} /$ epoxy composites. Colloids Surf. A 2009, 352, 88-93. [CrossRef]

22. Jun, Y.-W.; Huh, Y.-M.; Choi, J.-S.; Lee, J.-H.; Song, H.-T.; Kim, S.; Yoon, S.; Kim, K.-S.; Shin, J.-S.; Suh, J.-S.; et al. Nanoscale size effect of magnetic nanocrystals and their utilization for cancer diagnosis via magnetic resonance imaging. J. Am. Chem. Soc. 2005, 127, 5732-5733. [CrossRef] [PubMed]

23. Nan, C.-W.; Shen, Y.; Ma, J. Physical properties of composites near percolation. Annu. Rev. Mater. Res. 2010, 40, 131-151. [CrossRef]

24. Huang, X.; Xie, L.; Yang, K.; Wu, C.; Jiang, P.; Li, S.; Wu, S.; Tatsumi, K.; Tanaka, T. Role of interface in highly filled epoxy $/ \mathrm{BaTiO}_{3}$ nanocomposites. Part I-correlation between nanoparticle surface chemistry and nanocomposite dielectric property. IEEE Trans. Dielectr. Electr. Insul. 2014, 21, 467-479. [CrossRef]

25. Katayama, A.; Yuko, W.-T.; Inomata, T.; Ozawa, T.; Masuda, H. Theoretical Study of N2 Coordination to Titanocene (III) Monochloride in Ionic Liquid. Bull. Chem. Soc. Jpn. 2019, 92, 1379-1384. [CrossRef]

26. Min, Y.; Akbulut, M.; Kristiansen, K.; Golan, Y.; Israelachvili, J. The role of interparticle and external forces in nanoparticle assembly. Nat. Mater. 2008, 7, 527-538. [CrossRef] [PubMed]

27. Lewis, J.A. Colloidal processing of ceramics. J. Am. Ceram. Soc. 2000, 83, 2341-2359. [CrossRef]

28. Weil, E.D.; Levchik, S.V. Flame retardants in commercial use or development for polyolefins. J. Fire Sci. 2008, 26, 5-43. [CrossRef]

29. Hornsby, P.R. Fire retardant fillers for polymers. Int. Mater. Rev. 2001, 46, 199-210. [CrossRef]

30. Horrocks, A.R.; Price, D. Fire Retardant Materials; Woodhead Publishing: Abington, Cambridge, UK, 2001.

31. Kim, S. Flame retardancy and smoke suppression of magnesium hydroxide filled polyethylene. J. Polym. Sci. Part B 2003, 41, 936-944. [CrossRef]

32. Ramesh, S.; Shutzberg, B.A.; Huang, C.; Gao, J.; Giannelis, E.P. Dielectric nanocomposites for integral thin film capacitors: Materials design, fabrication and integration issues. IEEE Trans. Adv. Packag. 2003, 26, 17-24. [CrossRef]

33. Li, C.-C.; Chang, S.-J.; Lee, J.-T.; Liao, W.-S. Efficient hydroxylation of $\mathrm{BaTiO}_{3}$ nanoparticles by using hydrogen peroxide. Colloids Surf. A Physicochem. Eng. Asp. 2010, 361, 143-149. [CrossRef]

34. Zhou, T.; Zha, J.-W.; Cui, R.-Y.; Fan, B.-H.; Yuan, J.-K.; Dang, Z.-M. Improving dielectric properties of $\mathrm{BaTiO}_{3} /$ ferroelectric polymer composites by employing surface hydroxylated $\mathrm{BaTiO}_{3}$ nanoparticles. ACS Appl. Mater. Interfaces 2011, 3, 2184-2188. [CrossRef]

35. Fan, Y.; Wang, G.; Huang, X.; Bu, J.; Sun, X.; Jiang, P. Molecular structures of (3-aminopropyl) trialkoxysilane on hydroxylated barium titanate nanoparticle surfaces induced by different solvents and their effect on electrical properties of barium titanate based polymer nanocomposites. Appl. Surf. Sci. 2016, 364, 798-807. [CrossRef] 
36. Almadhoun, M.N.; Bhansali, U.S.; Alshareef, H.N. Nanocomposites of ferroelectric polymers with surface-hydroxylated $\mathrm{BaTiO}_{3}$ nanoparticles for energy storage applications. J. Mater. Chem. 2012, 22, 11196-11200. [CrossRef]

37. Kim, P.; Doss, N.M.; Tillotson, J.P.; Hotchkiss, P.J.; Pan, M.J.; Marder, S.R.; Perry, J.W. High energy density nanocomposites based on surface-modified $\mathrm{BaTiO}_{3}$ and a ferroelectric polymer. ACS Nano 2009, 3, 2581-2592. [CrossRef] [PubMed]

38. Wang, Z.; Qu, B.; Fan, W.; Hu, Y.; Shen, X. Effects of PE-g-DBM as a compatiblizer on mechanical properties and crystallization behaviors of magnesium hydroxide-based LLDPE blends. Polym. Degrad. Stab. 2002, 76, 123-128. [CrossRef]

39. Wang, Z.; Chen, Z.; Fan, W.; Nie, W. Effects of surface modifiers on mechanical and rheological properties of halogen-free flame retarded polyethylene composites. Polym.-Plast. Technol. Eng. 2006, 45, 191-196. [CrossRef]

40. Chen, X.; Yu, J.; Guo, S. Structure and properties of polypropylene composites filled with magnesium hydroxide. J. Appl. Polym. Sci. 2006, 102, 4943-4951. [CrossRef]

41. Huang, H.; Tian, M.; Yang, J.; Li, H.; Liang, W.; Zhang, L.; Li, X. Stearic acid surface modifying Mg (OH) 2: Mechanism and its effect on properties of ethylene vinyl acetate $/ \mathrm{Mg}(\mathrm{OH}) 2$ composites. J. Appl. Polym. Sci. 2008, 107, 3325-3331. [CrossRef]

42. Liauw, C.M.; Dumitru, P.; Lees, G.C.; Clemens, M.L.; Rothon, R.N. Interfacial Modification of Polystyrene-block-polybutadiene-block-polystyrene/Magnesium Hydroxide Composites, 1. Macromol. Mater. Eng. 2003, 288, 412-420. [CrossRef]

43. Schofield, W.; Hurst, S.; Lees, G.; Liauw, C.M.; Rothon, R.N. Influence of surface modification of magnesium hydroxide on the processing and mechanical properties of composites of magnesium hydroxide and an ethylene vinyl acetate copolymer. Compos. Interfaces 1997, 5, 515-528. [CrossRef]

44. Zhou, W.; Yu, D. Effect of coupling agents on the dielectric properties of aluminum particles reinforced epoxy resin composites. J. Compos. Mater. 2011, 45, 1981-1989. [CrossRef]

45. Sasikala, T.; Raman, S.; Mohanan, P.; Pavithran, C.; Sebastian, M.T. Effect of silane coupling agent on the dielectric and thermal properties of DGEBA-forsterite composites. J. Polym. Res. 2011, 18, 811-819. [CrossRef]

46. Badheka, P.; Magadala, V.; Devaraju, N.G.; Lee, B.I.; Kim, E.S. Effect of dehydroxylation of hydrothermal barium titanate on dielectric properties in polystyrene composite. J. Appl. Polym. Sci. 2006, 99, 2815-2821. [CrossRef]

47. Huang, X.; Xie, L.; Jiang, P.; Wang, G.; Liu, F. Electrical, thermophysical and micromechanical properties of ethylene-vinyl acetate elastomer composites with surface modified $\mathrm{BaTiO}_{3}$ nanoparticles. J. Phys. D Appl. Phys. 2009, 42, 245407. [CrossRef]

48. Huang, X.; Ma, Z.; Wang, Y.; Jiang, P.; Yin, Y.; Li, Z. Polyethylene/aluminum nanocomposites: Improvement of dielectric strength by nanoparticle surface modification. J. Appl. Polym. Sci. 2009, 113, 3577-3584. [CrossRef]

49. Anderson, R.A.; Lagasse, R.R.; Russick, E.M.; Schroeder, J.L. Effects of void size and gas content on electrical breakdown in lightweight, mechanically compliant, void-filled dielectrics. J. Appl. Phys. 2002, 91, 3205-3212. [CrossRef]

50. Zeng, X.; Yu, S.; Sun, R.; Du, R. Microstructure, thermal and dielectric properties of homogeneous bismaleimide-triazine/barium titanate nanocomposite films. Mater. Chem. Phys. 2011, 131, 387-392. [CrossRef]

51. Dalle Vacche, S.; Oliveira, F.; Leterrier, Y.; Michaud, V.; Damjanovic, D.; Månson, J.A.E. Effect of silane coupling agent on the morphology, structure, and properties of poly (vinylidene fluoride-trifluoroethylene)/BaTiO $\mathrm{B}_{3}$ composites. J. Mater. Sci. 2014, 49, 4552-4564. [CrossRef]

52. Quan, B.; Shi, W.H.; Ong, S.J.H.; Lu, X.; Wang, P.L.; Ji, G.; Xu, Z.J. Defect Engineering in Two Common Types of Dielectric Materials for Electromagnetic Absorption Applications. Adv. Funct. Mater. 2019, 29, 1901236. [CrossRef]

53. Sciences, E.M. Epofix Cold-Setting Embedding Resin. EMS Catalog \#1232. Available online: https: //www.emsdiasum.com/microscopy/technical/datasheet/1232.aspx (accessed on 21 March 2020).

54. Aldrich, S. Barium Titanate (IV) Nanopowder Specifications. Available online: https://www.sigmaaldrich.com/catalog/product/aldrich/256552?lang=en\&region=US\& gclid=Cj0KCQjw9tbzBRDVARIsAMBplx8633AyJoQwC8I68XXKjIQr-cc4DEji-rQ5g-Bn2iViXsvgfjqeoYaAvcnEALw_wcB (accessed on 21 March 2020). 
55. Sundar, U.; Lao, Z.C.; Cook-Chennault, K. Investigation of Piezoelectricity and Resistivity of Surface Modified Barium Titanate Nanocomposites. Polymers 2019, 11, 2123. [CrossRef]

56. Plueddemann, E.P. Silane coupling agents. Addit. Plast. 1978, 1, 123-167.

57. Dang, Z.-M.; Yuan, J.-K.; Zha, J.-W.; Zhou, T.; Li, S.-T.; Hu, G.-H. Fundamentals, processes and applications of high-permittivity polymer-matrix composites. Prog. Mater. Sci. 2012, 57, 660-723. [CrossRef]

58. Garnett, J.C.M. Colours in metal glasses and in metallic films. Proc. R. Soc. Lond. 1904, 73, 443-445. [CrossRef]

59. Garnett, J.C.M. Colours in metal glasses, in metallic films and in metallic solutions-II. In Proceedings of the Royal Society of London Series A-Containing Papers of a Mathematical and Physical Character; Royal Society: London, UK, 1905; Volume 76, pp. 370-373.

60. Koledintseva, M.Y.; Chandra, S.K.R.; DuBroff, R.E.; Schwartz, R.W. Modeling of dielectric mixtures containing conducting inclusions with statistically distributed aspect ratio. Prog. Electromagn. Res.-Pier 2006, 66, 213-228. [CrossRef]

61. Karkkainen, K.; Sihvola, A.; Nikoskinen, K. Effective permittivity of a random mixture with spherical inclusions. In Proceedings of the Igarss 2000: IEEE 2000 International Geoscience and Remote Sensing Symposium, Honolulu, HI, USA, 24-28 July 2000; Stein, T.I., Ed.; IEEE: Honolulu, HI, USA, 2000; Volume 1-6.

62. Karkkainen, K.K.; Sihvola, A.H.; Nikoskinen, K.I. Effective permittivity of mixtures: Numerical validation by the FDTD method. IEEE Trans. Geosci. Remote Sens. 2000, 38, 1303-1308. [CrossRef]

63. Sharma, R.; Sihvola, A. Studies on polarizabilities and scattering behavior of small spherical particles. Radio Sci. 2000, 35, 83-96. [CrossRef]

64. Gowdhaman, P.; Annamalai, V.; Thakur, O.P. Piezo, ferro and dielectric properties of ceramic-polymer composites of 0-3 connectivity. Ferroelectrics 2016, 493, 120-129. [CrossRef]

65. Wilson, P.M.; Lipatov, A.; Schmidt, D.; Schubert, E.; Schubert, M.; Sinitskii, A.; Hofmann, T. Structural and optical properties of cobalt slanted nanopillars conformally coated with few-layer graphene. Appl. Phys. Lett. 2015, 106, 231901. [CrossRef]

66. Nelson, S.; Kraszewski, A.; You, T. Solid and particulate material permittivity relationships. J. Microw. Power Electromagn. Energy 1991, 26, 45-51. [CrossRef]

67. Kiley, E.M.; Yakovlev, V.V.; Ishizaki, K.; Vaucher, S. Applicability Study of Classical and Contemporary Models for Effective Complex Permittivity of Metal Powders. J. Microw. Power Electromagn. Energy 2012, 46, 26-38. [CrossRef]

68. Simpkin, R. Derivation of Lichtenecker's Logarithmic Mixture Formula from Maxwell's Equations. IEEE Trans. Microw. Theory Tech. 2010, 58, 545-550. [CrossRef]

69. Zakri, T.; Laurent, J.P.; Vauclin, M. Theoretical evidence for 'Lichtenecker's mixture formulae' based on the effective medium theory. J. Phys. D-Appl. Phys. 1998, 31, 1589-1594. [CrossRef]

70. Jayasundere, N.; Smith, B.V. Dielectric-constant for binary piezoelectric 0-3 composites. J. Appl. Phys. 1993, 73, 2462-2466. [CrossRef]

71. Fan, L.; Rao, Y.; Tison, C.; Moon, K.S.; Pothukuchi, S.V.; Wong, C.P. Use of dispersant in high K polymer-ceramic nano-composite to improve manufacturability and performance of integral capacitors. In Proceedings of the 52nd Electronic Components and Technology Conference, San Diego, CA, USA, 28-31 May 2002; pp. $936-940$.

72. Rao, Y.; Takahashi, A.; Wong, C. Di-block copolymer surfactant study to optimize filler dispersion in high dielectric constant polymer-ceramic composite. Compos. Part A Appl. Sci. Manuf. 2003, 34, 1113-1116. [CrossRef]

73. Cho, S.-D.; Lee, J.-Y.; Hyun, J.-G.; Paik, K.W. Study on epoxy/BaTiO 3 composite embedded capacitor films (ECFs) for organic substrate applications. Mater. Sci. Eng. B 2004, 110, 233-239. [CrossRef]

74. Dang, Z.-M.; Wang, H.-Y.; Xu, H.-P. Influence of silane coupling agent on morphology and dielectric property in $\mathrm{BaTiO}_{3} /$ polyvinylidene fluoride composites. Appl. Phys. Lett. 2006, 89, 2902. [CrossRef]

75. Ramajo, L.; Reboredo, M.; Castro, M. Dielectric response and relaxation phenomena in composites of epoxy resin with $\mathrm{BaTiO}_{3}$ particles. Compos. Part A Appl. Sci. Manuf. 2005, 36, 1267-1274. [CrossRef]

76. Van Krevelen, D.; Hoftyzer, P. Their estimation and correlation with chemical structure. In Properties of Polymers; Elsevier: New York, NY, USA, 1976.

77. Huang, X.; Xie, L.; Yang, K.; Wu, C.; Jiang, P.; Li, S.; Tanaka, T. Role of interface in highly filled epoxy $/ \mathrm{BaTiO}_{3}$ nanocomposites. Part II-effect of nanoparticle surface chemistry on processing, thermal expansion, energy storage and breakdown strength of the nanocomposites. IEEE Trans. Dielectr. Electr. Insul. 2014, 21, 480-487. [CrossRef] 
78. Brosseau, C.; Achour, M. Variable-temperature measurements of the dielectric relaxation in carbon black loaded epoxy composites. J. Appl. Phys. 2009, 105, 124102. [CrossRef]

79. Fattoum, A.; Arous, M.; Gmati, F.; Dhaoui, W.; Mohamed, A.B. Influence of dopant on dielectric properties of polyaniline weakly doped with dichloro and trichloroacetic acids. J. Phys. D-Appl. Phys. 2007, 40, 4347-4354. [CrossRef]

80. Siddabattuni, S.; Schuman, T.P.; Dogan, F. Improved polymer nanocomposite dielectric breakdown performance through barium titanate to epoxy interface control. Mater. Sci. Eng. B 2011, 176, 1422-1429. [CrossRef]

81. Lewis, T. Interfaces: Nanometric dielectrics. J. Phys. D Appl. Phys. 2005, 38, 202. [CrossRef]

82. Ramajo, L.; Reboredo, M.M.; Castro, M.S. BaTiO 3 -epoxy composites for electronic applications. Int. J. Appl. Ceram. Technol. 2010, 7, 444-451.

83. Ogitani, S.; Bidstrup-Allen, S.A.; Kohl, P.A. Factors influencing the permittivity of polymer/ceramic composites for embedded capacitors. IEEE Trans. Adv. Packag. 2000, 23, 313-322. [CrossRef]

84. Rao, Y.; Ogitani, S.; Kohl, P.; Wong, C.P. Novel polymer-ceramic nanocomposite based on high dielectric constant epoxy formula for embedded capacitor application. J. Appl. Polym. Sci. 2002, 83, 1084-1090. [CrossRef]

85. Karimi, A.A.; Ahmad, Z. Effect of interface on the thermal mechanical properties of chemically bonded epoxy-silica hybrids. Prog. Org. Coat. 2017, 106, 137-144. [CrossRef]

86. Macan, J.; Ivankovic, H.; Ivankovic, M.; Mencer, H.J. Study of cure kinetics of epoxy-silica organic-inorganic hybrid materials. Thermochim. Acta 2004, 414, 219-225. [CrossRef]

(C) 2020 by the authors. Licensee MDPI, Basel, Switzerland. This article is an open access article distributed under the terms and conditions of the Creative Commons Attribution (CC BY) license (http://creativecommons.org/licenses/by/4.0/). 